\title{
Synthesis of trifunctional graft polymer polyether polyols employing a silica based gel as non-aqueous dispersant
}

\author{
Irene Izarra, D. Simón, M. Molina, J.F. Rodríguez, M. Carmona*
}

Chemical Engineering Department, University of Castilla-La Mancha, Institute of Chemical and

Environmental Technology, ITQUIMA, Avda. Camilo José Cela s/n, 13004, Ciudad Real, Spain.

*Corresponding author. Tel: 926295300 ext: 6709. E-mail address: Manuel.CFranco@uclm.es

\begin{abstract}
Currently, the PU industry is developing new products with enhanced physical, mechanical and structural properties. One of the specialties that is attracting more and more attention from managers and enterprises all over the world are the PUs based on polymer polyether polyols (graft polyols). In this work, the synthesis of graft polyols was developed employing a non-aqueous dispersant (NAD) based on silica gel, which contains in its chemical structure segments with a great affinity for the solid polymeric particles and other segment having a strong affinity for the hydroxyl groups of the liquid polyol. The combination of both polar and non-polar characteristics ensures the stability of the resulting polymer dispersion and prevent the sedimentation and the coalescence of the polymer particles. By using this NAD it was possible to synthesize trifunctional polymer polyether polyol (PPP) from Styrene and containing up to $38.69 \mathrm{wt} . \%$ of solids. The optimal reaction conditions have been stablished using a concentration of $1.5 \mathrm{wt} . \%$ NAD, $4 \mathrm{wt}$ \% of initiator respect to the monomer amount and a polymerization temperature of $80^{\circ} \mathrm{C}$. The viscosity of the optimal PPP (1930 mPa.s $)$ and the particle size ( $d v_{0.5}$ of $5.427 \mu \mathrm{m}$ and $d n_{0.5}$ of $1.711 \mu \mathrm{m}$ ) were in the range of graft polyols available in the market for similar solids content, with the additional advantage of employing a lower quantity of NAD and a softer reaction temperature than those employed in the industrial process $\left(110^{\circ} \mathrm{C}\right)$.
\end{abstract}

Keywords: graft polyol, polyurethane, silica gel, non-aqueous dispersant 


\section{Introduction}

Polyols are compounds with multiple hydroxyl functional groups employed as raw materials in the polyurethane (PU) sector. PUs are synthesized by means of the reaction between a polyol, which contains active hydroxyl groups, and an isocyanate; giving as result a substituted carbamic acid ester or urethane. At present, PU is one of the most important kinds of polymers with a global production of 17.565 million tons [1]. The diversity of polyols and isocyanates allows the synthesis of numerous different specialties covering a huge range of applications. Depending of the kind of the polyol and isocyanate employed in the formulation, PU can be classified in foams or in the denominated CASEs (Coatings, Adhesives, Sealants and Elastomers). Furthermore, foams can be flexible, such as the ones used in mattresses and automotive seats [2], and rigid, which are involved in buildings isolation [35] and commercial refrigeration [6]. On the other hand, CASEs are used in sporty shoes, electronic products and in shipbuilding industry [7].

Nowadays, the global tendency in the PU market is the development of new products with enhanced properties in comparison to the regular ones based on conventional polyols, either polyether or polyesters polyols.

It is well known in the PU industry that the employment of polyols containing inorganic fillers, mainly $\mathrm{BaSO}_{4}$ or $\mathrm{CaCO}_{3}$, improves in a substantial way the hardness and the load bearing properties of the final synthesized PU. These inorganic loads act as nucleating agents during the foaming process and aid in cell opening at the end of the rise process, causing changes in the average cell size of the PU structure $[8,9]$. In a general way, PU foams created by means of polyols containing inorganic fillers present greater density values, resulting in greater hardness properties, however, in most of the cases worsen other properties, such as remaining deformation, tensile strength and elongation.

Solid organic polymers can be also employed as PU fillers in order to enhance the density and hardness of PU without causing an important deteriorating of the above commented mechanical properties [8]. These polyols containing polymer microparticles are known as polymer polyether 
polyol (PPP or filled polyols) and now a days they are among the most demanded types of polyol [10]. Taking into account the nature of the polymer solid particles, PPP can be classified in the following categories: graft polyether polyols (vinylic polymers and copolymers); polyurea dispersion polyols (PHD polyols); polyurethane dispersion polyols (PIPA polyols) [11] and other PPP (epoxy or aminoplast dispersion) [8].

Graft polyether polyols are produced by polymerizing one or more ethylenically unsaturated monomers dissolved or dispersed into a polyether polyol (PP, carrier or base polyol) in the presence of a free radical polymerization initiator. The synthesis of these graft polyols is widely described in literature by means of innovation patents [12-22].

Among the monomers generally used in this patents, it can be found; acrylic acid, methacrylic acid, methylacrylate, methyl methacrylate, ethylacrylate and the acrylamides, such as acrylamide and methacrylamide; vinyl compounds, such as vinyl chloride (VCM) and vinylidene chloride; acrylonitrile (ACN); styrene (SM), brominated styrenes, such as dibromostyrene, tribromostyrene and mixtures of these: $\alpha$-methylstyrene and p-methylstyrene [23]. Nevertheless, some of the monomers most employed for the synthesis of graft polyether polyols are: ACN, SM, $\alpha$-methyl styrene methylmethacrylate, hydroxyalkyl acrylates and methacrylates and VCM [8], being the ACN and SM the most demanded for industrial production [8]. In most cases, the monomer was added together with a chain transferitor to reduce the viscosity and the polymerization initiator to a mixer, preparing this way the initiator solution. Thus, independently of the monomers used in the synthesis of PPP, this usually contains a solid concentration between 55-60\%. The difficulty lies in obtaining economically profitable systems by synthesizing stable polymer polyols with high solids content and low viscosity [23].

On the other hand, the most used methods for stabilizing graft polyols consist of the generation in situ of the non-aqueous dispersant (NAD) by grafting reactions, producing macromers with or without polymerisable double bonds. 
The reactive NAD is formed by means of chain transfer reactions during the radical polymerization of vinylic monomers in the liquid polyether media whereas non-reactive NADs do not contain polymerisable double bonds. The non-reactive NAD is constituted by two parts of different nature; an organic section that presents great affinity for the polymeric particles and a high molecular weight polyether chain, which has high affinity for the continuous liquid polyether polyol (PP). According to the latest publications, the use of macromers as NAD with terminal double bonds, capable of copolymerizing with vinyl monomers and forming graft species during radical copolymerization is widespread. The most used reagent to generate double bonds, by the reaction with hydroxyl groups, is maleic anhydride. But generally, the use of this type of macromers originates PPP with high viscosities. [23-25].

At present, the efforts in the graft polyether polyols industry are focused in enhancing the stability of the polymeric dispersions to get high solids content values and moderate viscosity, since high viscosity values make difficult their processing. Consequently, the research in new kind of NADs is a high priority topic for the polyols industry.

Hence, this paper focusses its attention in the synthesis of graft polymer polyether polyols employing a novel NAD based on silica gel as stabilizing polymer. This NAD contains in the same structure a segment with a great affinity for the solid polymeric particles and a second segment containing hydroxyl groups with a strong affinity for the PP, ensuring the stability of the resulting polymer dispersion and preventing the sedimentation and the coalescence of the vinylic polymer particles. For producing a stable trifunctional PPP containing a huge concentration of solid particles and the proper viscosity, styrene and NAD concentrations within 30-40 and 1.5-5 wt.\%, respectively, initiator/monomer mass ratios between 0.833 to $4.0 \mathrm{wt} . \%$ and a polymerization temperature from $70^{\circ} \mathrm{C}$ to $110^{\circ} \mathrm{C}$ were studied. The characteristics of the PPP were analysed by Master Sizer, GPC, SEM, FTIR, TGA and ${ }^{1} \mathrm{H}$ MNR. 


\section{Materials and methods.}

\subsection{Materials.}

The reagents employed for the synthesis of the PPP were a trifunctional polyol with an average molecular weight of $3500 \mathrm{~g} / \mathrm{mol}$ and a hydroxyl number of $48 \mathrm{mgKOH} / \mathrm{g}$ supplied by Repsol, called F4811, the chain transfer agent 1-Dodecanothiol 98\% (NDDM) and Styrene monomer 98\% from Sigma Aldrich, the initiator 2-2'-Azobis (2-methylpropionitrile) (AIBN) from Fluka Analytical. Tetraethylorthosilicate 98\% (TEOS), Vinyltriethoxysilane 97\% (VTES) and Sodium Hydroxide (1M, $\mathrm{NaOH})$ supplied by Sigma Aldrich, Clorhidric acid $(\mathrm{HCl}, 2 \mathrm{~N})$ from VWR and Mili-Q water were used as reagents for the NAD synthesis.

\subsection{Polymer polyether polyol synthesis.}

\subsubsection{Monomer treatment.}

Three extraction operations were carried out for removing the commercial SM inhibitor. A solution of $\mathrm{NaOH} 1 \mathrm{M}$ was used. For each extraction the same $\mathrm{SM} / \mathrm{NaOH}$ mass ratio was employed. Finally, two extractions with milli-Q water were carried out at equal mass proportions. The styrene resulting from these extraction processes was stored in a sealed vessel, containing desiccant sieves for removing the remaining water.

\subsubsection{Polymerization reaction.}

The synthesis of PPP was carried out under atmospheric pressure at laboratory scale in a reaction equipment designed for that purpose. The installation consists of a glass-lined reaction vessel with a capacity of $0.25 \mathrm{~L}$, thermostated within $-20-200^{\circ} \mathrm{C}$ with polyethylene glycol 400 using a circulator Ultraterm 200 from Selecta. In the upper part the reactor is connected to a reflux condenser, circulating dried $\mathrm{N}_{2}$ to maintain an inert atmosphere, a temperature indicator and a digital agitation head Heidolph RZR 2041 ranged from 40 to $2000 \mathrm{rpm}$. The agitation system was isolated using silicone seal. 
Firstly, the polyol is added to the reactor and immediately the nitrogen stream is fed to generate an inert environment, connecting the reflux condenser, the agitation rate at $900 \mathrm{rpm}$ and fixing the temperature set-point at 70,80 or $110^{\circ} \mathrm{C}$. When the temperature of the system reached the set point value, the NAD was added to the reactor, maintaining the mixture under agitation for $10 \mathrm{~min}$.

Otherwise, the SM, the initiator (AIBN) and the chain transfer agent (NDDM) were weighed, mixed and put into an oven at a pre-reaction temperature of $50{ }^{\circ} \mathrm{C}$ for $40-50$ minutes, depending on the monomer percentage.

Finally, the above mixture was added to the reactor. The addition time was function of PPP solids content, for 30 or $40 \mathrm{wt} . \%, 6$ or 13 minutes, respectively. The dispersion polymerization reaction was stopped after 5 hours.

\subsubsection{Determination of PPP solids content.}

Once the PPP has been synthesized, the solid concentration was quantified by ${ }^{1} \mathrm{H}$ NMR. The technique employed using ${ }^{1} \mathrm{H}$ NMR is described by Bharti et al. According to them, NMR spectra is directly proportional to the number of nuclei responsible of that particular resonance [26]. The molar ratio between two compounds, can be calculated by means of the following expression (Ec.1):

$$
\frac{M_{P S}}{M_{P P}}=\frac{I_{P S}}{I_{P P}} \cdot \frac{N_{P P}}{N_{P S}}
$$

where PS and PP are the polystyrene and the polyether polyol, respectively, I, N and M are the area of the resonance peak, the number of nuclei and the corresponding molar mass.

The polystyrene area was obtained by subtracting from the whole spectrum area, the polyol and the styrene areas. In this case, the styrene area was quantified by considering the resonance of the hydrogen in the alpha position, which is characteristic of the unreacted double bonds of styrene monomer. From these areas, it was possible to determine the mass ratios PS/PPP and SM/PPP for PPPs. By using these mass ratios and the initial monomer, it is also possible to determine the SM loss during the reaction process as function of the obtained PPP ( $\left.\mathrm{SM}_{\text {loss }} / \mathrm{PPP}\right)$, as follow (Ec. 2): 


$$
\frac{S M_{\text {LosS }}}{P P P}=\frac{0.4-(P S / P P P+S M / P P P)}{0.6}
$$

Once the three mass ratios have been obtained, the initial monomer amount was split into converted monomer or polystyrene (PS), unreacted monomer (SM) and the monomer loss ( $\left.\mathrm{SM}_{\mathrm{loss}}\right)$.

\subsection{Non-aqueous dispersant synthesis. Interaction with PS and PP.}

\subsubsection{NAD reaction.}

NAD synthesis has been carried out by means of the Stöber process, in which the hydrolysis and condensation reactions of the alcoxilane precursors take place [27-31].

Two different mixtures from each alcoxilane (TEOS or VTES) containing EtOH, milli-Q water and $\mathrm{HCl}$, were prepared. Molar ratios of TEOS/VTES, $\mathrm{H}_{2} \mathrm{O} / \mathrm{TEOS}-\mathrm{VTES}$ and EtOH/TEOS-VTES of 0.5, 2.5 and 4, respectively, were used to synthesize the stabilizer. The mixtures were maintained under agitation at $300 \mathrm{rpm}$, during 60 minutes for promoting the hydrolysis reactions of TEOS and VTES. Further, these solutions were mixed at a stirring rate of $500 \mathrm{rpm}$, keeping the reaction for 60 minutes. Finally, the mixture was neutralized with an alkaline solution of sodium hydroxide (pH 9).

\subsubsection{Bulk polymerization of PS, NAD-PS and NAD-PP.}

The study of the NAD interaction with the PP and SM were performed in a reactor of $50 \mathrm{ml}$ under inert atmosphere.

The synthesis of bulk polymerization of SM was carried out at $80^{\circ} \mathrm{C}$, employing 8 gr of $\mathrm{SM}$ and 0.2 gr of initiator (2.5 wt.\% respect to the SM content). The NAD-PS copolymerization was prepared at the same temperature and employing $8,0.2$ and 1.8 gr of SM, AIBN and NAD, respectively. The polymerization reaction of both experiments was accomplished at $400 \mathrm{rpm}$ for 1 hour.

Finally, the linkage between PP and NAD was studied at $80^{\circ} \mathrm{C}$, at a stirring rate of $400 \mathrm{rpm}$ and during 10 minutes of reaction, employing 10 and $1.5 \mathrm{gr}$, respectively.

\subsection{Sample characterization}

\subsubsection{Viscosity.}


The viscosity of the PPP was obtained by using a Bohlin Gemini rheometer. The rheological measurements at a fixed temperature of $25^{\circ} \mathrm{C}$ were carried out at a continuous oscillation of $96 \mathrm{~Hz}$, an equilibrium time of 60 s and a controlled stress of $250 \mathrm{~N} / \mathrm{m}^{2}$. The cone and plate measuring systems was used, utilizing a cone angle of $4^{\circ}, 40 \mathrm{~mm}$ of diameter and $0.15 \mathrm{~mm}$ of gap.

\subsubsection{GPC.}

Gel Permeation Chromatography, GPC, was used to determine the molecular weight (MW) distribution of the PPP and its polydispersity by using polyether polyols standards with reported MW remaining from 100 to 20000 .

The different measurements are made with a Viscotek TDAmax chromatograph with two columns (Styragel HR2 and Styragel HR0.5) at $35^{\circ} \mathrm{C}$ with a flow of $1 \mathrm{ml} / \mathrm{min}$ and tetrahydrofuran (THF) as eluent.

\subsubsection{Particle Size Distribution.}

The Malvern Mastersizer 2000 equipment was used to determine the particle size of the dispersed polymers polyols. The equipment was capable of measuring in the range of 0.02 to $2000 \mu \mathrm{m}$. The dispersion of the samples was done with the accessory 2000 SM Hydro using ethanol as a dispersing agent.

\subsubsection{Infrared spectroscopy.}

The chemical structure of the NAD and the chemical interaction of each synthesized polyol were confirmed by Fourier transform infrared spectrometer. Infrared spectra were obtained with a spectrophotometer Varian 640-IR type FT-IR in the range 4000 to $600 \mathrm{~cm}^{-1}, 8 \mathrm{~cm}^{-1}$ resolution and 16 scans, with the program Varian Resolutions Pro Software, version 5.0.

\subsubsection{SEM Analysis.}

The internal morphology structure of the polyols was obtained by means of Scanning Electron Microscopy (SEM) by using a FEI QUANTA 200. 


\subsubsection{Thermogravimetric analysis.}

Thermal degradation properties of the polymer polyether polyols were obtained by TGA, using a TA Instrument equipment model SDT Q600. The used conditions for each analysis were a heating rate of $10^{\circ} \mathrm{C} / \mathrm{min}$ from room temperature to $700{ }^{\circ} \mathrm{C}$ under nitrogen atmosphere.

\subsubsection{Nuclear Magnetic Resonance (NMR)}

The ${ }^{1} \mathrm{H}$ NMR spectra were recorded on Bruker Ascend TM-500/400 spectrometer and referenced to the residual deuterated solvent.

\section{Results and discussion}

\subsection{Trifunctional polymer polyether polyols.}

As it has been previously commented, the most demanded monomers for industrial production of graft polyols are ACN and SM [8]. The higher the proportion of $\mathrm{ACN}$, the higher the amount of generated in situ NAD species, because of the greater reactivity and polarity of this monomer in comparison to SM. In consequence, in the present study, it was decided to synthesize PPP exclusively based in SM (monomer with very high stability) with the aim of ensuring that the NAD proposed is able to provide a proper stabilization, regardless the employment of ACN in the synthesis of the graft polyols.

It is a well-known fact that polyols can form hydrogen bonds with the hydroxyl groups of the silicon $[32,33]$. On the other hand, Agudelo et al, reported the formation of polystyrene-graft-silica particles using copolymers based on SM and VTES and confirmed by ${ }^{1} \mathrm{H}$ NMR, FTIR and TGA [34].

The described NAD ensures a proper stabilization of the vinylic polymer particles into the polyol media by a conjunction of two effects, hydrogen bonds formation between the ether oxygen atoms or the hydroxyl groups of the polyol with the NAD hydroxyl groups [33, 35], and the reactivity of the vinyl groups of the NAD with SM [34].

A scheme showing the stabilization and growing up of the dispersed polyether polyol phase is presented in Fig. 1. 


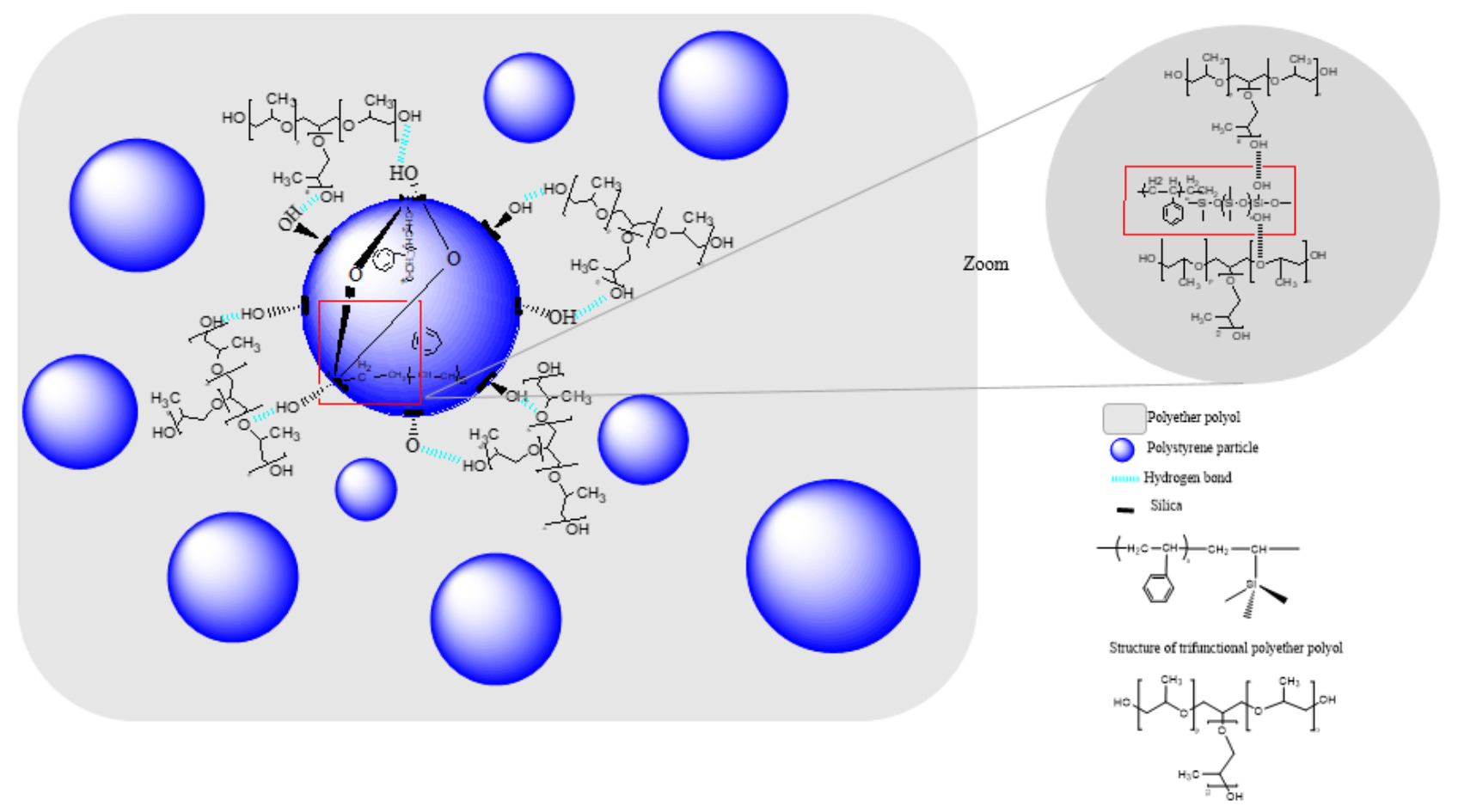

Fig. 1. Partial condensation of the hydrolyzed alcoxilanes with the trifunctional base polyol and steric effect of the generated NAD.

\subsubsection{Non-Aqueous Dispersant: NAD-PP and NAD-PS interaction.}

The use of silica-based compounds having hydroxyl and double bonds as groups which are able to stabilize a polymeric dispersion based on the alcoxilanes Tetraorthosilicate (TEOS) and Vinyltriethoxysilane (VTES) has not been reported in literature.

The proposed chemical structure of the synthesized NAD is shown in Fig. 2. This NAD presents, hydroxyl groups with high affinity for the base polyether polyol, and vinyl groups that are attached to the particles of polystyrene. In this way, a proper stabilization is achieved and at the same time the flocculation is avoided. 


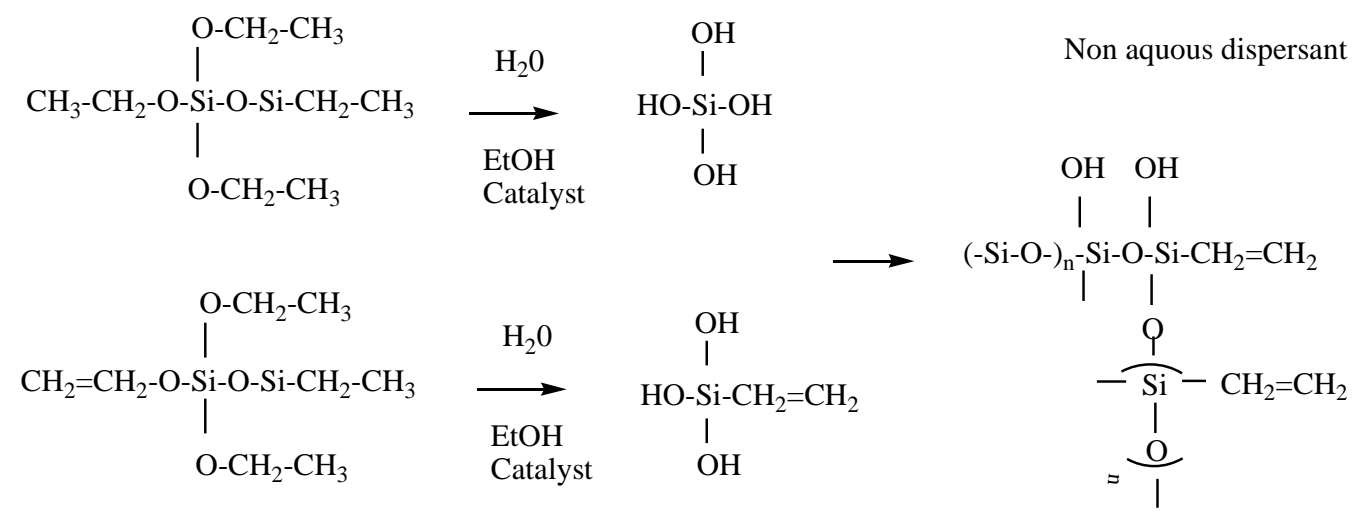

a)

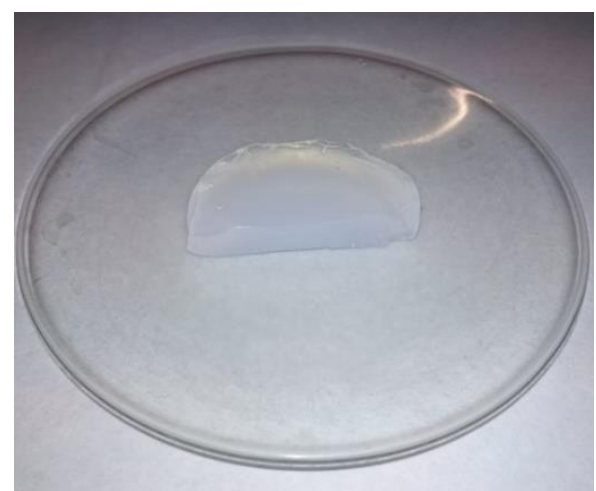

b)

Fig. 2. Chemical structure and physical aspect of NAD a) chemical mechanism and b) gel product.

To know the interaction of NAD with the polyol and PS, the products NAD-PP and NAD-PS were obtained by bulk polymerization and characterized by TGA, FTIR and ${ }^{1} \mathrm{H}$ NMR.

\section{- Characterization NAD-PP}

In Fig. 3 are shown the TGA and FTIR analyses of the NAD-PP produced by bulk polymerization to know the interaction between NAD and PP.

Thermogravimetric analyses of pure NAD, PP and NAD-PP are presented in Fig. 3a). It can be clearly seen how the degradation temperature of the pure NAD is almost complete at $80^{\circ} \mathrm{C}$ being the inorganic silica remained as a residue at $700^{\circ} \mathrm{C}$. This weight loss is due to the presence of ethanol and water in the structure of the NAD synthesized. On the other hand, the degradation temperature of the polyether polyol base can be seen at $370{ }^{\circ} \mathrm{C}$, which is largely displaced to the right when the degradation of 
NAD-PP is observed, owing to the presence of the inorganic silica and the polyol linkage. This behaviour can be due to the linkage between silanol groups and PP through hydrogen bonding, where ethereal oxygen atom of the polyol acts as the hydrogen bond acceptor [32].

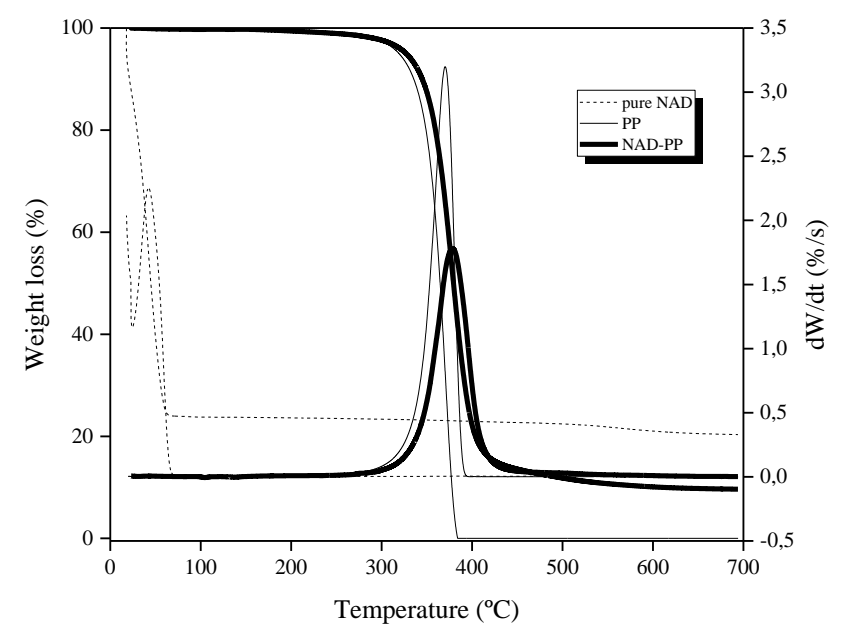

a)

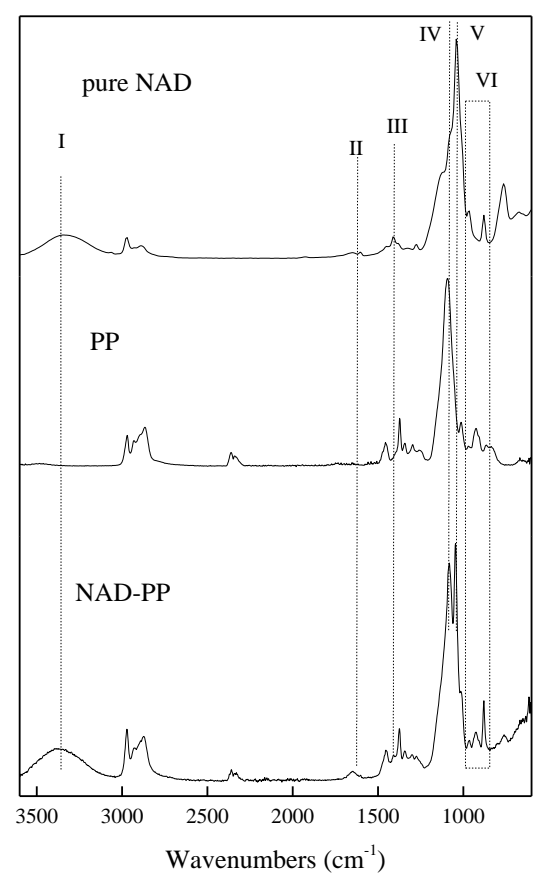

b)

Fig. 3. Thermogravimetric a) and FTIR b) analysis of NAD-PP interaction.

In Fig. 3b) shows FTIR spectra for pure NAD, PP and NAD-PP. In the first one is observed the typical peaks of the functional groups of NAD. The signal $3419 \mathrm{~cm}^{-1}$ (Peak I) corresponds to the hydrogen bond formed by the silanol groups of NAD while the Peaks II, III and VI are representative signals for vinyl groups $\left(\mathrm{Si}-\mathrm{CH}_{2}=\mathrm{CH}_{2}\right), 1600,1410$ and $960 \mathrm{~cm}^{-1}$, respectively [36]. Vibrations of Si-O-Si bonds correspond to Peak V. The hydrogen bonds between the polyol and the non-aqueous dispersant can be observed in Peak I, whereas the vinyl groups of the dispersant (Peak II) are observed in the NAD-PP spectrum, respectively. While, one of the characteristics peaks of $\mathrm{Si}-\mathrm{CH}_{2}=\mathrm{CH}_{2}$ (Peak VI, $960 \mathrm{~cm}^{-1}$ ) can be weakly detected, Peak II may have overlapped with PP vibrations. Finally, a combination of Peak IV, characteristic of PP, and Peak V, characteristic of NAD, can be seen in the NAD-PP spectra. 
Fig. 4 shows the interactions between PP and NAD, where it can be easily observed the formed hydrogen bonds between the hydroxyl groups of NAD with either hydroxyl groups or ethereal oxygen atoms of the polyol.

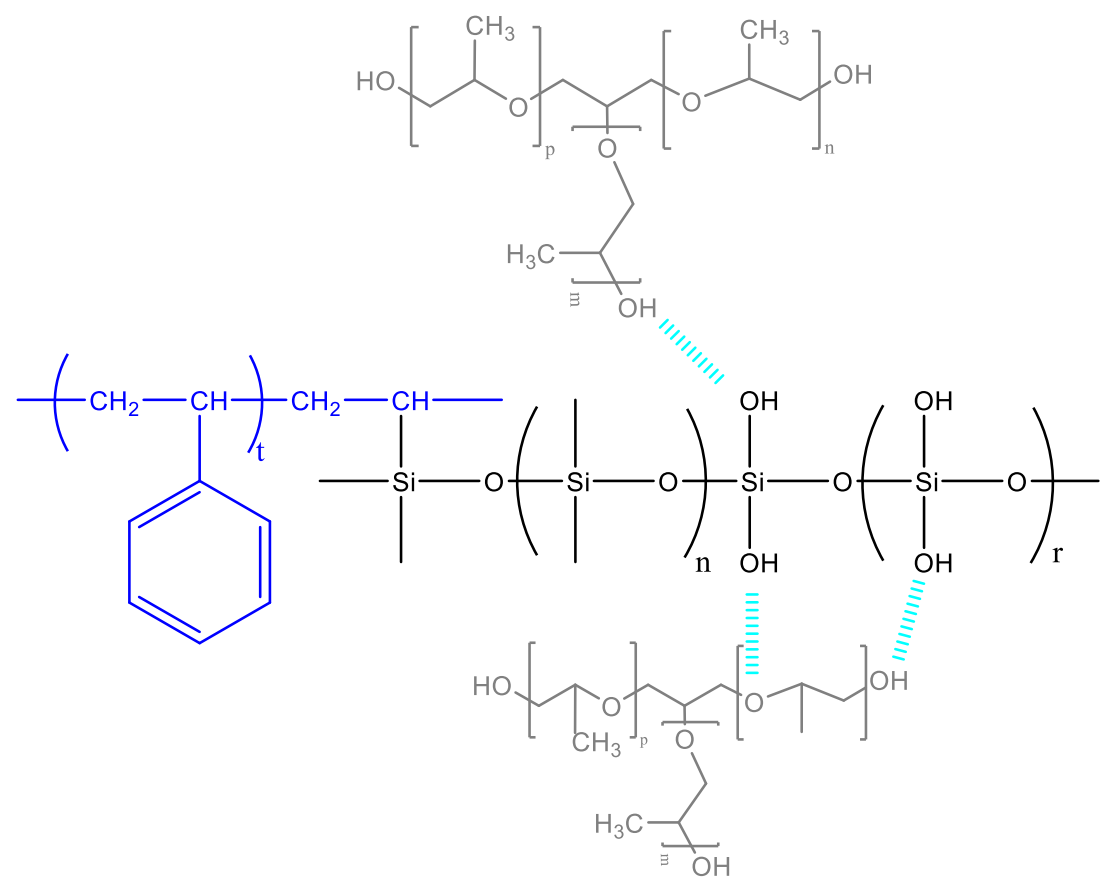

Fig. 4. Structure of NAD-PP interaction.

Fig. 5 shows the ${ }^{1} \mathrm{H}$ NMR spectra of PP and NAD-PP obtained by bulk polymerization. In PP spectrum, the signals located between 1.3-1 ppm are assigned to $\mathrm{CH}_{3}-\mathrm{CH}_{2^{-}}$, and they can be observed as multiplets owing to tactic/isotactic orientation of these groups $[37,38]$. The resonances between 3.6-3.2 ppm are assigned to the ethylene signals of the polyether polyol and to the $-\mathrm{CH}$ - connected to $\mathrm{OH}$ [37]. Consequently, a new resonance is observed at $3.9 \mathrm{ppm}$ (peak f), assigned to $-\mathrm{CH}_{2}-\mathrm{O}$, due to the interaction between the terminated hydroxyl groups of the PP and the NAD [39]. Therefore, the resonances between 3.7-3.1 and 1.3-1 ppm in PP-NAD spectrum are broader and more intense compare with PP ${ }^{1} \mathrm{H}$ NMR, indicating a stronger interaction between hydrogen species [40]. Then, the higher intensity of the previous resonances and the presence of a new peak at $3.9 \mathrm{ppm}$ (peak f), confirm the interaction between NAD and PP. 


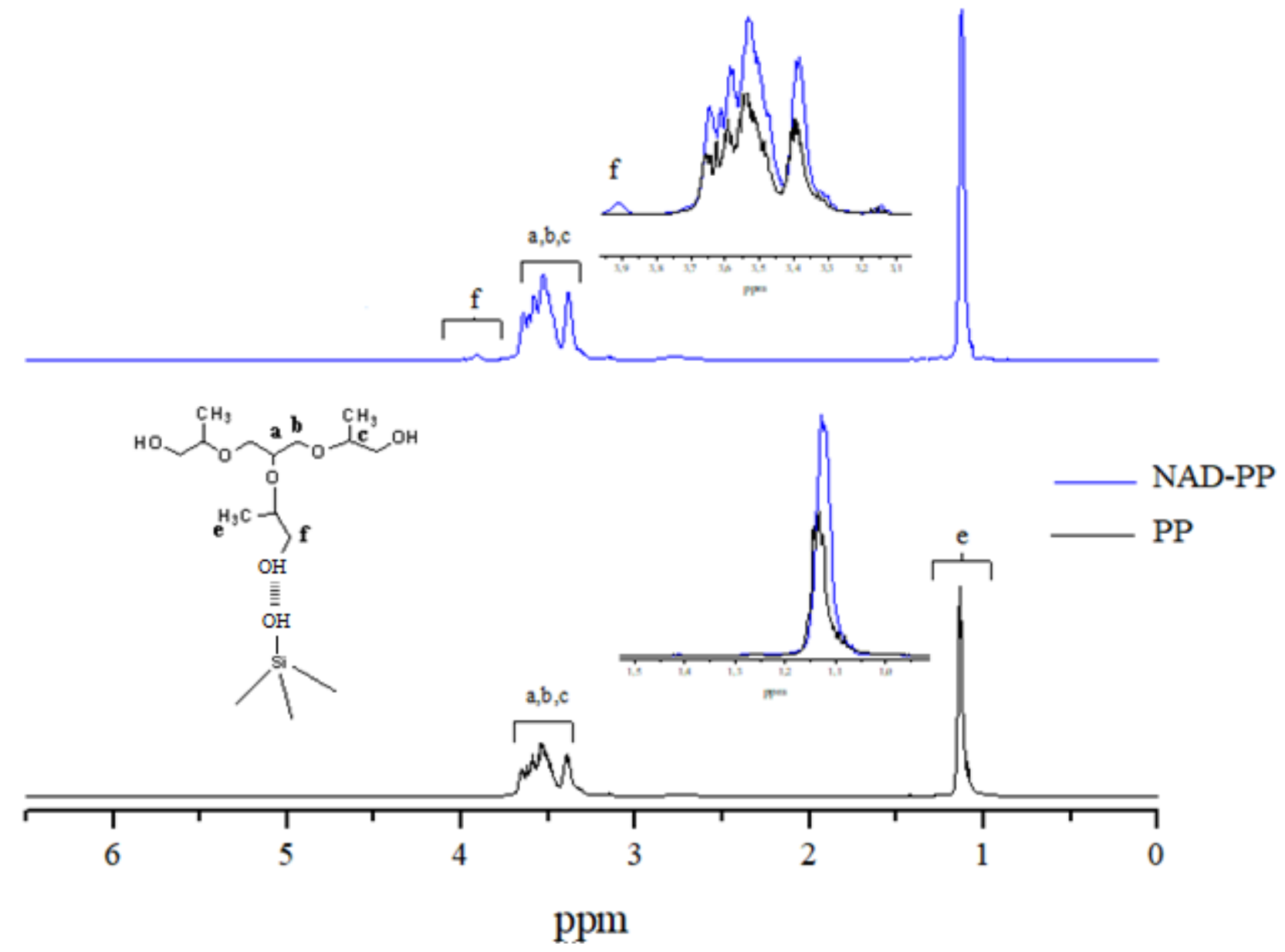

Fig. 5. ${ }^{1} \mathrm{H}$ NMR spectra for pure polyol (PP) and NAD-PP obtained by bulk polymerization.

\section{- Characterization NAD-PS.}

TGA and FTIR of the graft reaction between the NAD and PS are presented in Fig. 6. TGA of the products NAD, PS and NAD-PS produced by bulk polymerization are presented in Fig. 6a). In the spectra PS and NAD-PS can be seen two different weight losses; the first one corresponds to unreacted SM, and the second one is due to the degradation of both polymers, PS and NAD-PS copolymer. It can be clearly seen how the degradation temperature of the NAD-PS polymer is shifted to the right, confirming the grafting reaction between the SM and vinyl group of the NAD. At the same time, the residue of this copolymer increased by the inorganic silica presence.

Fig. $6 \mathrm{~b}$ ) shows the FTIR analyses of the products previously commented. It can be checked within $1369-1264 \mathrm{~cm}^{-1}$ (Peak II) the presence of $\mathrm{Si}_{-} \mathrm{CH}_{2}-$ band, characteristic for being weaker indeed [36]. Vibrations originated by the rupture of the NAD double bonds in the graft polymerization reaction 
between the dispersant and the SM. This peak could not be seen in Fig. 6b) because it might be overlapped with the characteristic wavelengths of the polyether polyol. Finally, the intense peak observed in region IV corresponds to the typical strong C-H bends of PS.

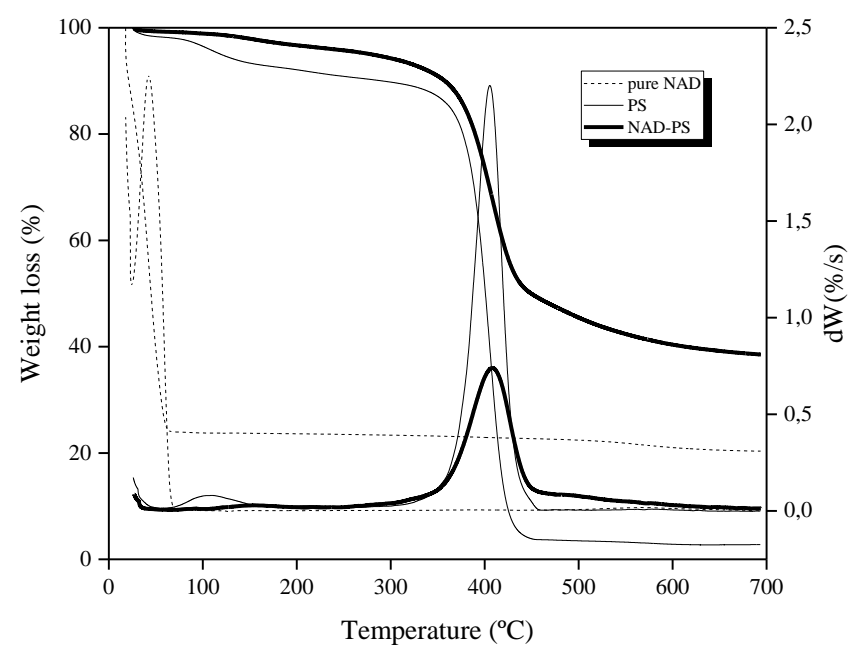

a)

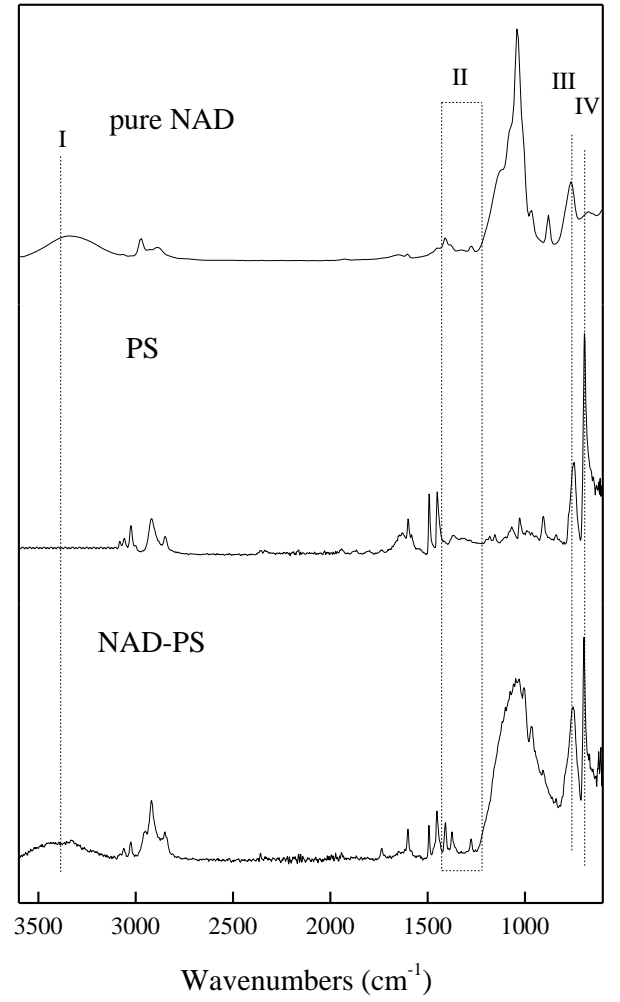

b)

Fig. 6. Thermogravimetric a) and FTIR b) analysis of NAD-PS graft polymerization.

The structure of the NAD-PS copolymer can be observed in Fig. 7.

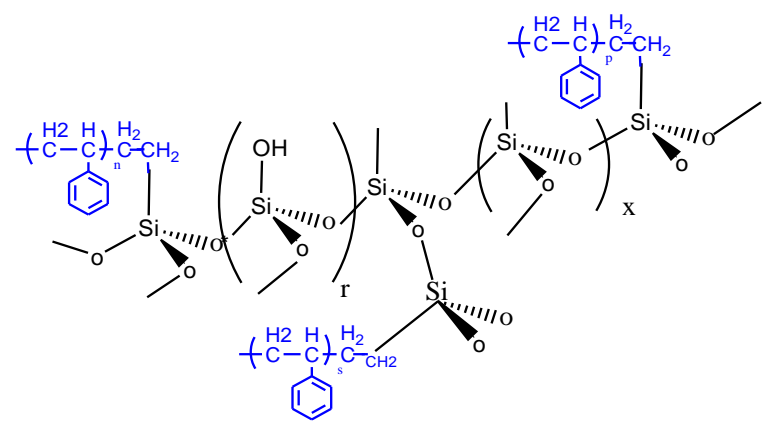

Fig. 7. Structure of the NAD-PS copolymer 
Lastly, in Fig. 8 is presented the PS and NAD-PS ${ }^{1} \mathrm{H}$ NMR spectra.

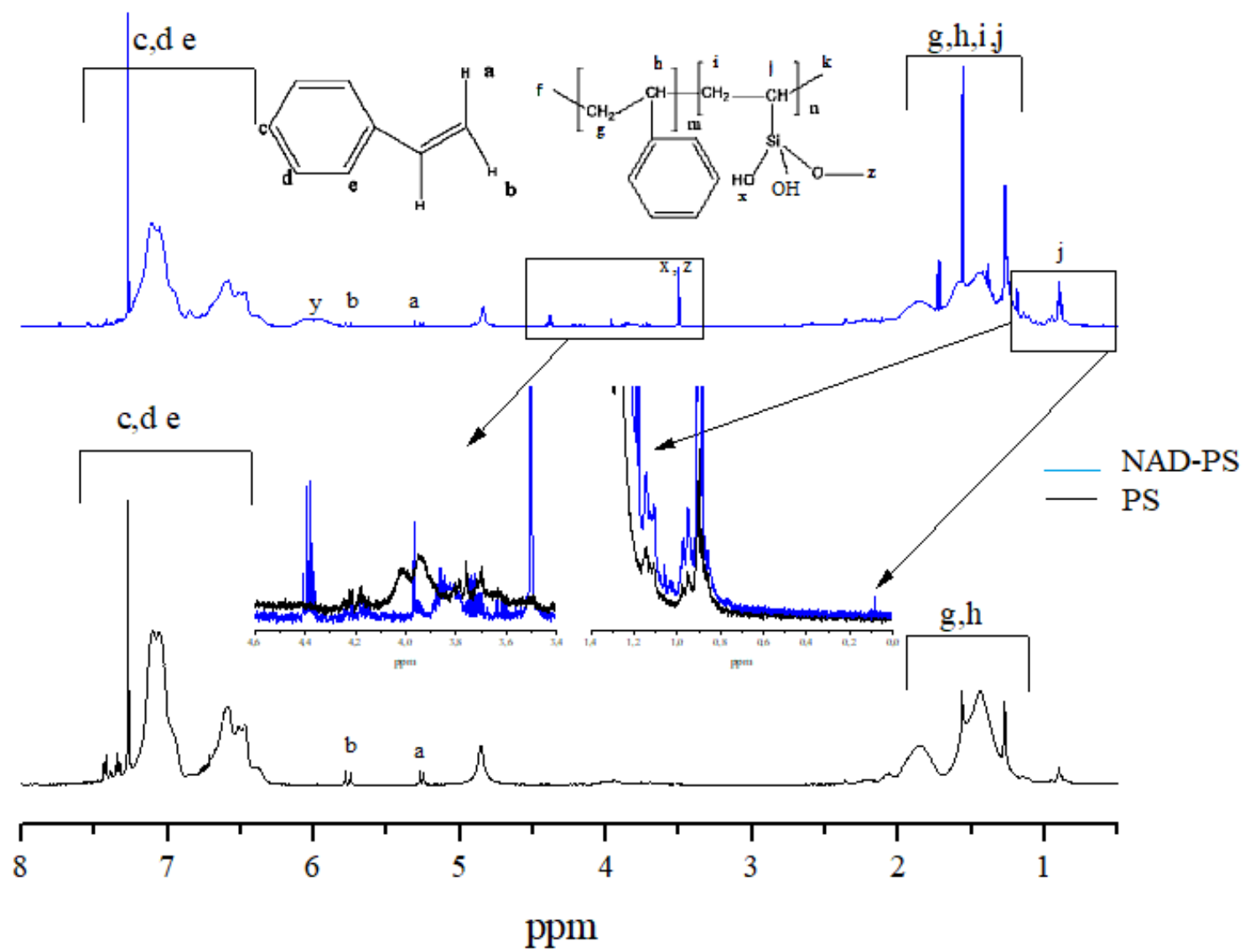

Fig. 8. Spectra of ${ }^{1} \mathrm{H}$ NMR for PS and NAD-PS.

The characteristic resonance peaks for aromatic protons can be seen in both spectra between 6 and $7.5 \mathrm{ppm}(\mathrm{c}, \mathrm{d}, \mathrm{e})$. The signals between 6 and $5 \mathrm{ppm}$ correspond to the alpha hydrogens of the unreacted $\mathrm{SM}(\mathrm{a}, \mathrm{b})$. The unlinked $\mathrm{Si}-\mathrm{CH}_{2}=\mathrm{CH}_{2}$ can be detected at $6 \mathrm{ppm}(\mathrm{y})$ [41]. Likewise, peaks due to aliphatic chains can be found between 0.9 and $2.2 \mathrm{ppm}(\mathrm{g}, \mathrm{h})$, whereas the signal of silanol groups (x), only detectable in NAD-PS spectrum, were observed between 4 and 3.4 ppm. Hence, the new signals within 1.4-0.9 ppm indicate the presence of $\mathrm{Si}-\mathrm{CH}_{2}-\mathrm{CH}_{2-}$ groups, which confirms the graft polymerization [41]. Besides, this grafting can be also confirmed by the weak proton resonance of hydrogen in the alpha position to the silicon atom that appears at a signal within $0.2-0.1 \mathrm{ppm}$. This resonance was also reported by other authors using VTES as a monomer [42]. The above results confirm that NAD can react with SM, leading grafting polymers. 


\subsubsection{Synthesis of the polymer polyether polyols.}

Once the NAD synthesis and characterization were defined, a study about the NAD and AIBN concentration was carried out, taking as starting point the PPP recipe described in literature. Table 1 shows the PPP formulation, in terms of weight percentage with respect to the total reaction mass.

Table 1. Polymer polyether polyol recipe.

\begin{tabular}{|c|c|}
\hline Reactive & Concentration (wt.\%) \\
\hline Monomer (M): Styrene (SM) & $30-40$ \\
\hline Non-aqueous dispersant (NAD) & $1.5-5$ \\
\hline Polyol: Alcupol F4811 (PP) & $66-57$ \\
\hline Chain transferitor: NDDM & 0.5 \\
\hline Initiator: IM & $0.625-4$ \\
\hline
\end{tabular}

*(/M) Weight percentage relative to the monomer content.

Table 2 shows the experiments that were performed for obtaining the PPP varying the content of $\mathrm{NAD}, \mathrm{IM}$ and $\mathrm{SM}$, keeping constant the temperature at $110^{\circ} \mathrm{C}$ and employing an agitation rate of 900 $\operatorname{rpm}[43]$.

Each PPP was defined as $P P P_{X}$ being $X$ the corresponding experiment, and it will be refer as $\mathrm{P}_{\mathrm{A}} \mathrm{I}_{\mathrm{B}} \mathrm{N}_{\mathrm{C}}$ as follows; the first character P, represent the PPP, and A is indicative of the amount of monomer (\%.wt), the second character, I, represents the initiator, being B the IM multiplied by thousand, and finally, the third character, $\mathrm{N}$, represents the NAD, being $\mathrm{C}$ its weight percentage multiplied by ten. 
Table 2. Set of experiment.

\begin{tabular}{|c|c|c|c|c|c|}
\hline Experiment & Nomenclature & $\begin{array}{c}\text { Reaction } \\
\text { temperature } \\
\left({ }^{\circ} \mathrm{C}\right)\end{array}$ & $\begin{array}{l}\text { Monomer, M } \\
\quad(w t . \%)\end{array}$ & $\begin{array}{c}\mathrm{IM} \\
(\mathrm{wt} . \%)\end{array}$ & $\begin{array}{l}\text { NAD } \\
\text { (wt.\%) }\end{array}$ \\
\hline $\mathrm{PPP}_{1}$ & P30I833N50 & \multirow{8}{*}{110} & \multirow{2}{*}{30} & \multirow[t]{2}{*}{0.833} & 5 \\
\hline $\mathrm{PPP}_{2}$ & P30I833N30 & & & & \multirow[b]{2}{*}{3} \\
\hline $\mathrm{PPP}_{3}$ & P40I625N30 & & \multirow{6}{*}{40} & \multirow{3}{*}{0.625} & \\
\hline $\mathrm{PPP}_{4}$ & P40I625N20 & & & & 2 \\
\hline $\mathrm{PPP}_{5}$ & P40I625N15 & & & & \multirow{4}{*}{1.5} \\
\hline $\mathrm{PPP}_{6}$ & P40I1250N15 & & & 1.25 & \\
\hline $\mathrm{PPP}_{7}$ & P40I2500N15 & & & 2.5 & \\
\hline $\mathrm{PPP}_{8}$ & P40I4000N15 & & & 4 & \\
\hline
\end{tabular}

With the aim of determining the best condition for obtaining a stable PPP with the lower viscosity and highest solid content, some parameters as viscosity, morphology, particle size, molecular weight distribution, thermogravimetric analysis and ${ }^{1} \mathrm{H}$ NMR have been studied. Fig. 9 shows as example the physical aspect of the synthesized graft polyols (P40I4000N15), and its stability after aging or centrifugation.

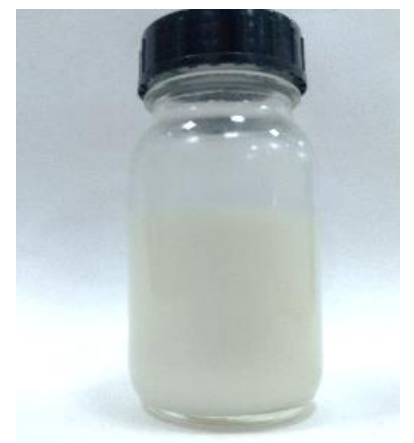

a)

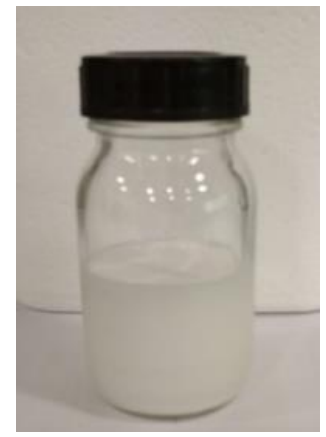

b)

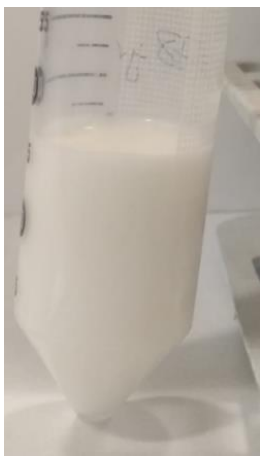

c)

Fig. 9. Graft polyol P40I4000N15 a) Recently-created b) after aging and c) under centrifugation In this figure can be observed that this product was completely stable after aging ( 5 months) or under applying centrifugal force field during $20 \mathrm{~min}$ at $3800 \mathrm{rpm}$.

In order to confirm the presence of the typical groups present in the graft polyols some FTIR analyses are showed in Fig. 10. 
It can be observed three peaks in the PPP spectra. Peak I is located at $1495 \mathrm{~cm}^{-1}$ and corresponds with double bonds $\mathrm{C}=\mathrm{C}$ of the unreacted monomer adsorbed on the polystyrene particles, while Peaks II and III (780 and $700 \mathrm{~cm}^{-1}$, respectively) are typical ones of polystyrene [44-47]. It must be noted that the higher the amount of monomer employed, the greater the intensity of these bands. It is also crucial to remark that these peaks are not present in the base polyether polyol (Alcupol F-4811) FTIR, indicating the presence of polystyrene particles in the polyol media.

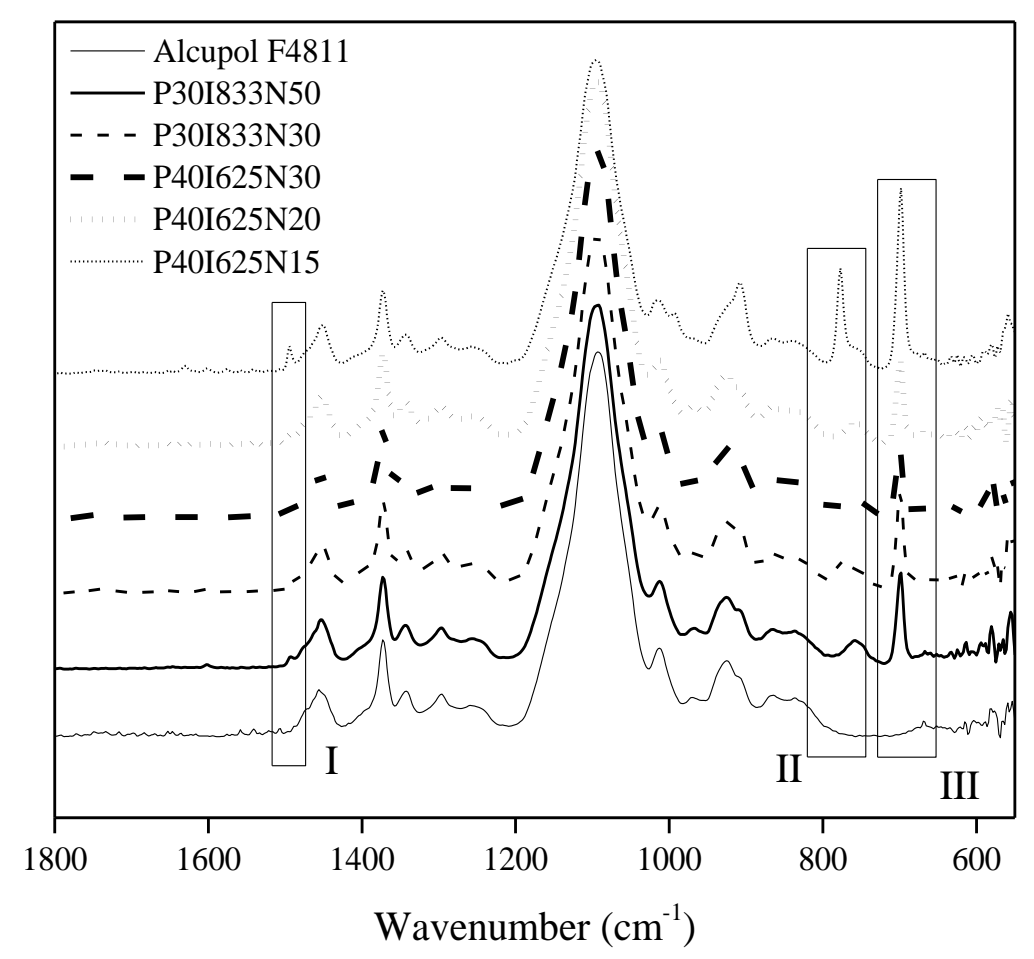

Fig. 10. Comparison of the FTIR spectra of the base polyether polyol with the synthesized graft polyols.

The influence of SM, NAD and IM could be seen by studying the viscosity of the obtained products in Fig. 11. 


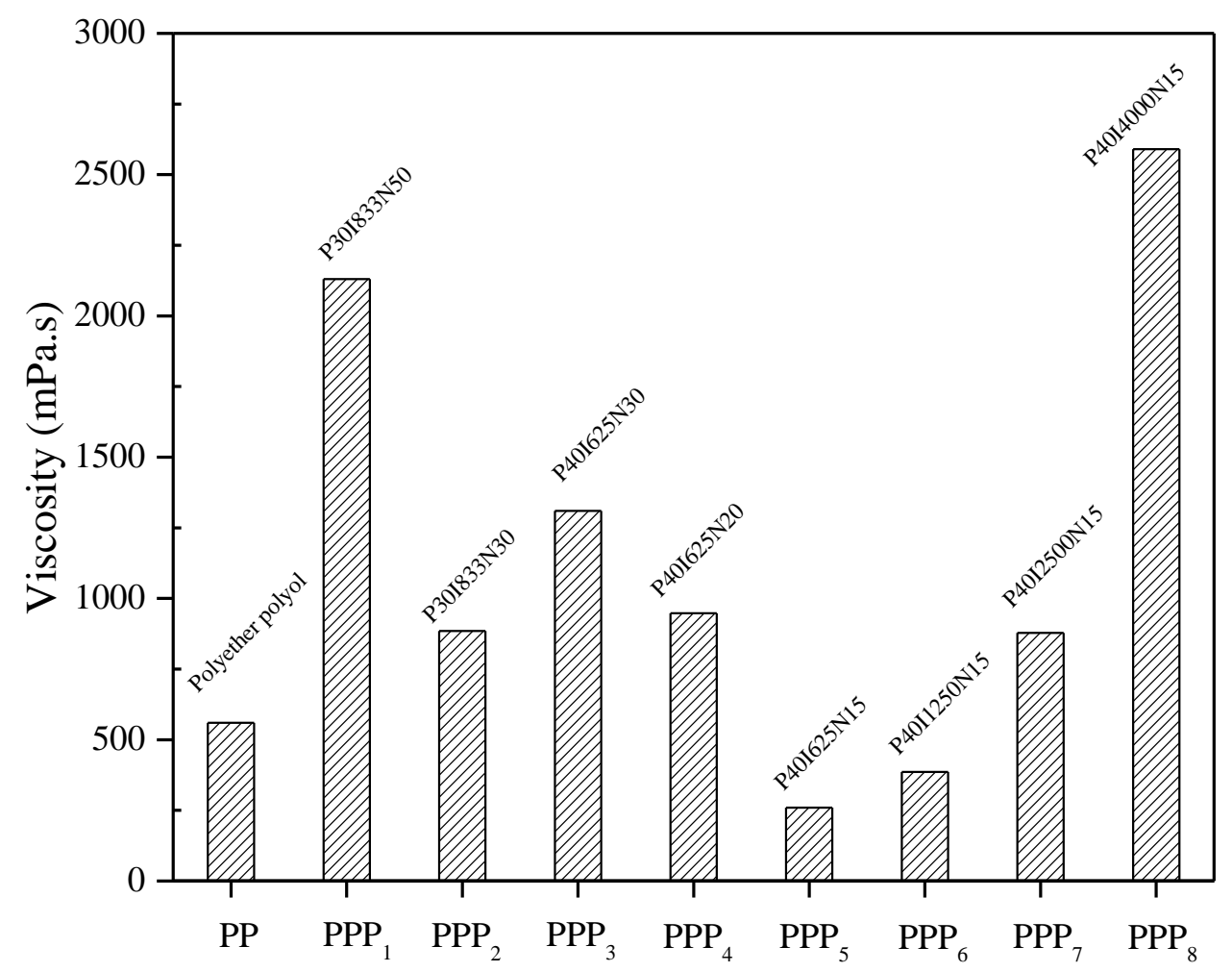

Fig. 11. Dynamic viscosity of the obtained products.

As it can be appreciated, all products have much higher viscosity than exhibited by the PP, except $\mathrm{PPP}_{5}$ and $\mathrm{PPP}_{6}$. This indicates clearly that a proper combination between IM and NAD concentrations is required. Observing that for a minimum NAD (1.5 wt.\%), a value of IM much higher than 1.25 wt.\% must be used, in order to achieve a larger polymer production. On the other hand, the higher the NAD concentration, the higher the viscosity of the PPP, when the IM weight percentage is kept constant $\left(\eta \mathrm{PPP}_{1}>\eta \mathrm{PPP}_{2}\right.$ and $\left.\eta \mathrm{PPP}_{3}>\eta \mathrm{PPP}_{4}>\eta \mathrm{PPP}_{5}\right)$, indicating a lower amount of unreacted monomer. These results are in agreement with Ionescu M [8] and Málaga M [43]. Thus, the NAD reactivity has a great influence on the polymerization nucleation process, either by improving the monomer conversion or leading products of high particle size.

Regarding the viscosity it could be increased by using larger concentrations of NAD or initiator. 
Fig. 12 shows the SEM micrographs for the different PPP products and in Fig. 12 is shown the particle size distribution (PSD) of these products as function of the NAD and IM concentrations.

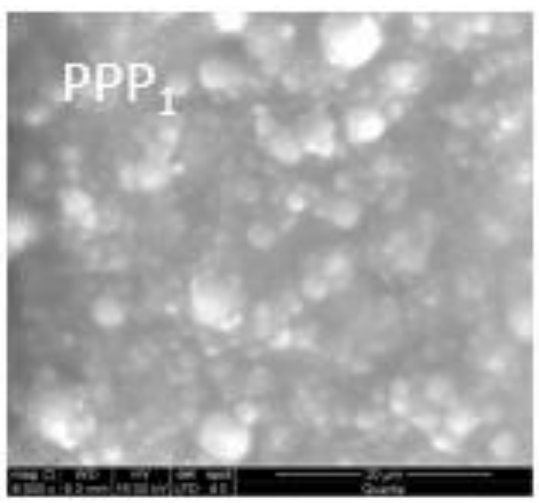

a) P30I833N50

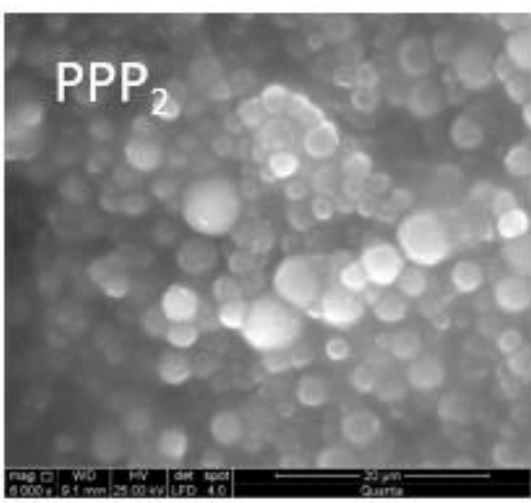

b) P30I833N30

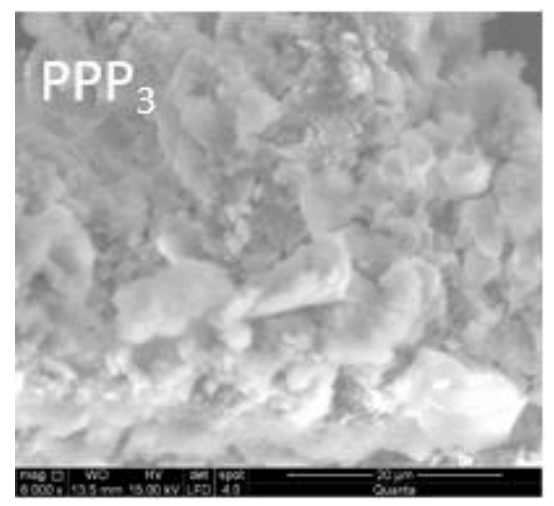

c) $\mathrm{P} 40 \mathrm{I} 625 \mathrm{~N} 30$

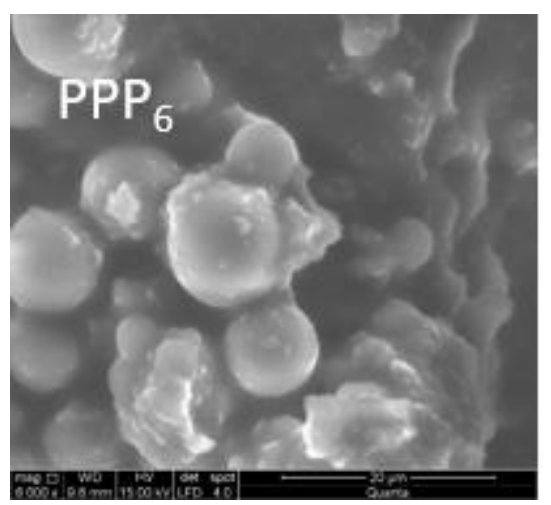

f) $\mathrm{P} 40 \mathrm{I} 1250 \mathrm{~N} 15$

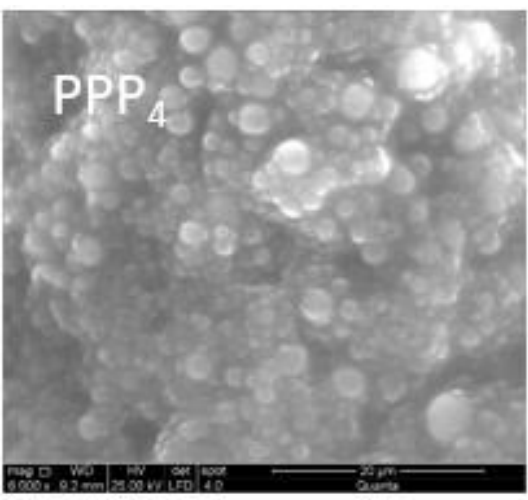

d) P40I625N20

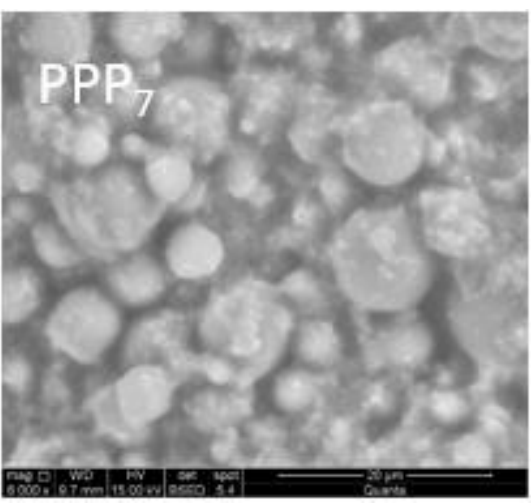

g) P40I25005N15

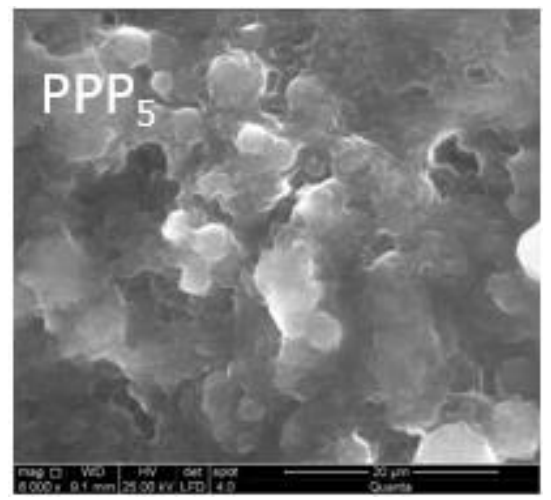

e) P40I625N15

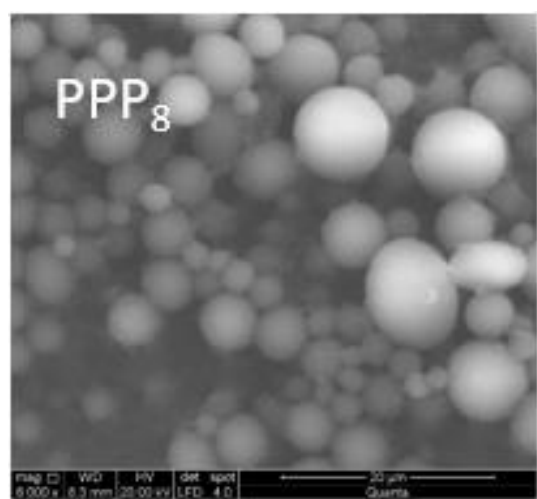

h) P40I40005N15

Fig. 12. SEM micrographs with x6000 magnification and particle size distribution of the synthesized PPPs.

Fig.13 shows the particle size distribution of the all synthesized PPPs. 


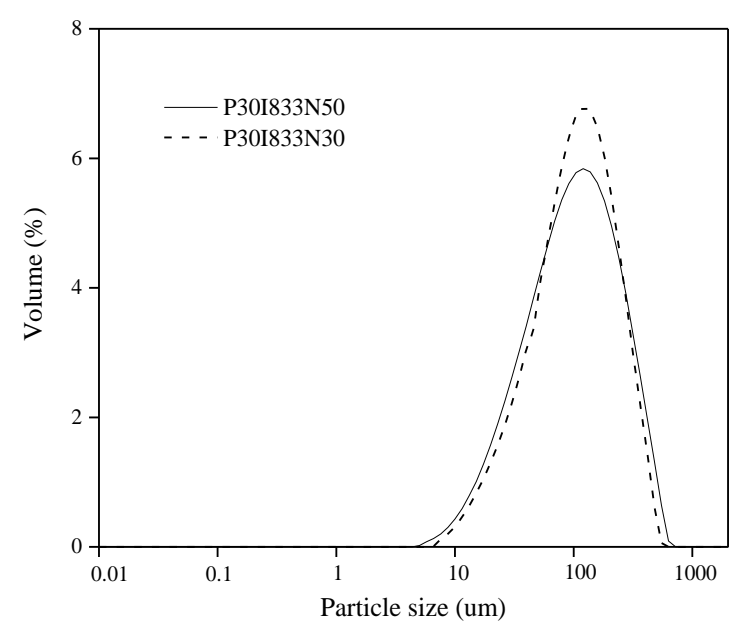

a)

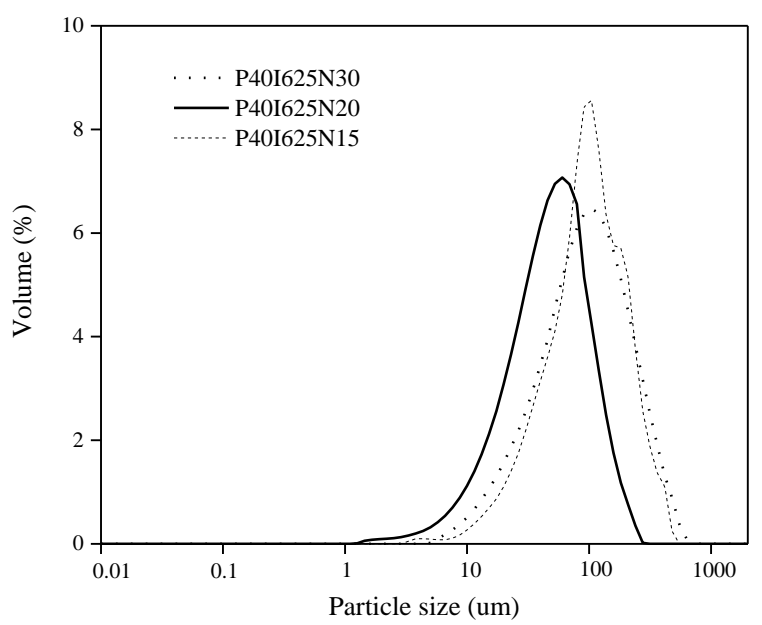

b)

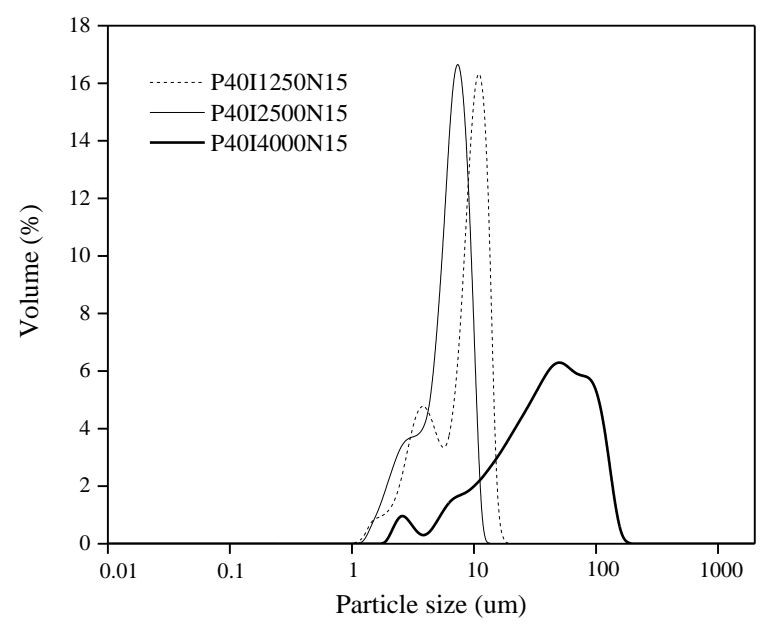

c)

Fig. 13. Influence of the particle size distribution by changing the initiator concentration, a) 0.833 wt.\%, b) 0.625 wt. $\%$ and c) at a fixed NAD concentration of $1.5 \mathrm{wt} . \%$.

In Fig. 12 is observed that PPPs obtained from monomers and initiator concentrations of 30 and 0.833 wt.\% are constituted by spherical particles of polystyrene, exhibiting a wide particle size distribution in volume $\left(\mathrm{dp}_{\mathrm{v} 0.5}\right)$ ranged between 5 to $700 \mu \mathrm{m}$ (Fig. 13a). Micrographs c), d) and e) from Fig. 12 confirm that the NAD concentration is an important variable in the production of PPP. The best morphology (spherical particles) of the product was obtained when a 2 wt. $\%$ of NAD was used, given the narrowest PSD within 1.27-278 $\mu \mathrm{m}$, whereas the other two products present a broad PSD similar to those of $\mathrm{PPP}_{1}$ and $\mathrm{PPP}_{2}$. Finally, micrographs $\mathrm{f}$ ), g) and h) show the effect of the initiator concentration on the morphology. Fig. 12h) displays a terminated polystyrene product perfectly 
formed by single particles completely spherical, having a smooth surface and a particle size in the $\mu \mathrm{m}$ range, but leading a polydisperse PPP. This behaviour was also observed by Málaga M. He found that, increasing the IM concentration would cause a large nucleation process, producing a polymeric product having higher solid content and lower unreacted monomer, but with higher polydispersity that can be diminished with temperature. On the other hand, the particles obtained by using an initiator concentration lower than $4.0 \mathrm{wt} . \%$ seem to be cover by a non-terminated polymer, indicating that a higher amount of indicator is required for completing the polymerization reaction. Hence, attending to the above results, combining the effects of initiator and non-aqueous dispersant, it is possible to obtain the proper conditions for synthesizing a PPP. According to the maximum viscosity exhibited by the $\mathrm{PPP}_{8}$ (Fig. 11) and the identity point of the particles (Fig. 12h) obtained by using IM and NAD concentrations of 4 and $1.5 \mathrm{wt} . \%$, respectively, it is possible to infer that a proper monomer conversion was achieved at these conditions.

Attending to the above results and in order to find the effect of the NAD on the PPP production, the highest IM concentration was selected for further considerations. In that way, the obtained $\mathrm{PPP}_{5}$ to $\mathrm{PPP}_{8}$ were analysed. Fig. 14 shows the GPC chromatograms with the aim of confirming the SM polymerization in the polyether polyol media.

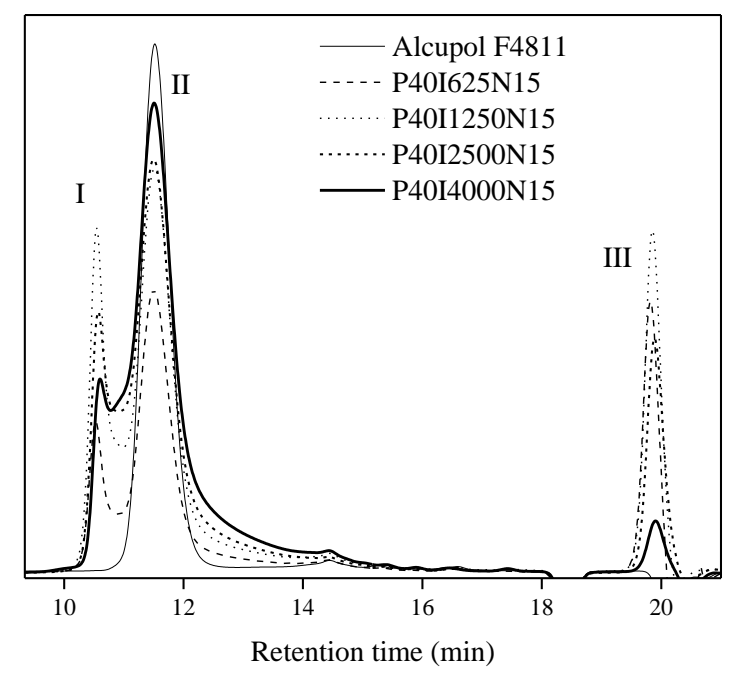

Fig. 14. Characterization by GPC of the base polyether polyol and graft polyols Peak I: PS; Peak II: PP. Peak III: Unreacted SM. 
In all the chromatograms presented above it can be observed three different peaks; Peak I, correspond to the polystyrene particles (PS) in the polyether polyol (PP) media, Peak II, correspond to the proper polyether polyol, and Peak III is related to the unreacted SM. All the experiments present a significant concentration of polystyrene particles (Peak I) dispersed in the polyether polyol (Peak II). The molecular weight of PS and PP and their polydispersities ( $\mathrm{D}_{\mathrm{PS}}$ and $\left.\mathrm{D}_{\mathrm{PP}}\right)$ are gathered in Table 3.

Table 3. Average molecular weights of PS and PP and their polydispersities for each product.

\begin{tabular}{cccccc}
\hline & \multicolumn{2}{c}{ PS } & \multicolumn{2}{c}{ PP } \\
\hline \multicolumn{2}{c}{ Polymer polyether Polyol } & $\mathrm{M}_{\mathrm{W}}(\mathrm{g} / \mathrm{mol})$ & $\mathrm{D}_{\mathrm{PS}}$ & $\mathrm{M}_{\mathrm{w}}(\mathrm{g} / \mathrm{mol})$ & $\mathrm{D}_{\mathrm{PP}}$ \\
\hline $\mathrm{PP}$ & & --- & --- & 3533 & 1.06 \\
\hline $\mathrm{PPP}_{5}$ & $\mathrm{P} 40 \mathrm{I} 625 \mathrm{~N} 15$ & 14788 & 1.09 & 3578 & 1.17 \\
\hline $\mathrm{PPP}_{6}$ & $\mathrm{P} 40 \mathrm{I} 1250 \mathrm{~N} 15$ & 14450 & 1.09 & 3550 & 1.13 \\
\hline $\mathrm{PPP}_{7}$ & $\mathrm{P} 40 \mathrm{I} 2500 \mathrm{~N} 15$ & 13912 & 1.08 & 3592 & 1.25 \\
\hline $\mathrm{PPP}_{8}$ & $\mathrm{P} 40 \mathrm{I} 4000 \mathrm{~N} 15$ & 13288 & 1.09 & 3567 & 1.32 \\
\hline
\end{tabular}

According to the previous data, the average PS molecular weight tends to decrease with the increase of the initiator concentration, observing the GPC chromatograms, the narrower the Peak I, the lower the retention time, which defines the molecular weight. The wide of the peak is related to the molecular weight polydispersity and the compound concentration can be estimated from the area under the peak. PS polymers present similar polydispersity although the molecular weight decreases with the initiator concentration. From the area under the peak III can be obtained that a higher SM conversion can be reached at high initiator concentration. The minimum area was obtained for the P40I4000N15. On the other hand, Peak II has a wide-ranging tendency when higher concentrations of initiator are employed, and with a slightly shifting to the left of its maximum peak signal respect to the PP peak.

It can be clearly observed that the lower the IM concentration the higher the unreacted SM (Peak III), which agrees to the viscosity values previously obtained $\left(\eta \mathrm{PPP}_{5}<\eta \mathrm{PPP}_{6}<\eta \mathrm{PPP}_{7}<\eta \mathrm{PPP}_{8}\right)$.

Additionally, the thermogravimetric analysis technique allows us to detect the presence of unreacted SM. Then, thermogravimetric analyses of the PPP changing the IM concentration were studied with 
the aim of obtaining the thermal stability. In Fig. 15, it can be observed the TGA changing the initiator concentration.

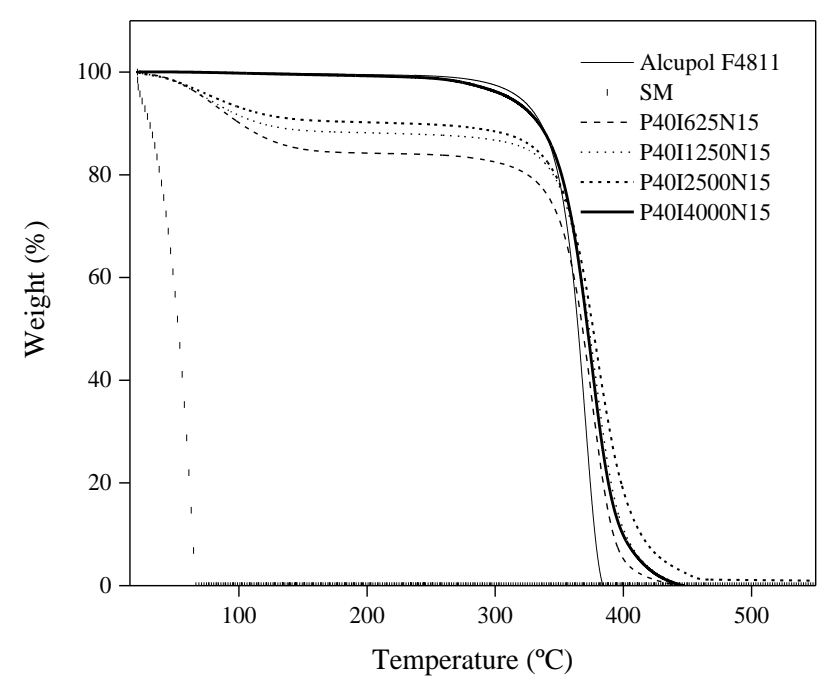

a)

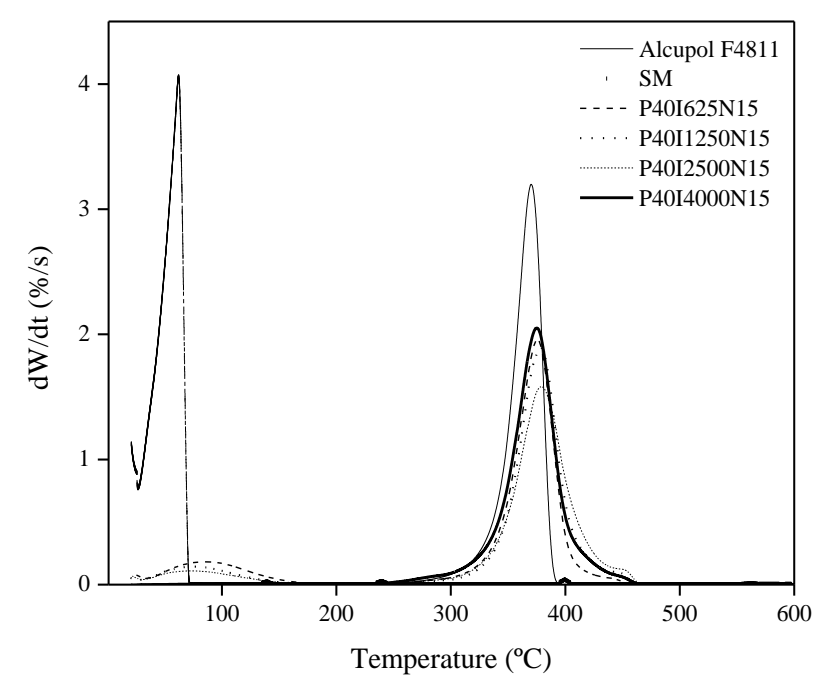

b)

Fig. 15. Thermogravimetric analysis of the PPP varying the amount of IM.

It can be appreciated two different weight of losses, the first one $\left(145^{\circ} \mathrm{C}\right)$ corresponds to the unreacted SM, and the second one refers to the degradation of PS particles and the PP. From the first weight loss, the percentage of unreacted monomer for each PPP can be estimated, obtaining 14.99, 11.58, 9.45 and 0.0 wt.\% for $\mathrm{PPP}_{5}, \mathrm{PPP}_{6}, \mathrm{PPP}_{7}$ and $\mathrm{PPP}_{8}$, respectively. Then, by TGA could be confirmed that the higher the IM concentration, the lower the quantity of unreacted monomer in the final product, achieving the highest SM conversion by using 4 wt.\% of AIBN respect to the monomer. This behaviour confirms the above observations taken out from the GPC chromatograms, where it was easily observed that the higher the AIBN concentration the lower the area of unreacted monomer peak. Attending to the highest unreacted monomer of the $\mathrm{PPP}_{5}$ respect to the others, this product was discarded for further considerations.

Regarding to the solid quantification, the ${ }^{1} \mathrm{H}$ NMR spectra of $\mathrm{PP}, \mathrm{PPP}_{6}, \mathrm{PPP}_{7}$ and $\mathrm{PPP}_{8}$, are shown in Fig 16. 


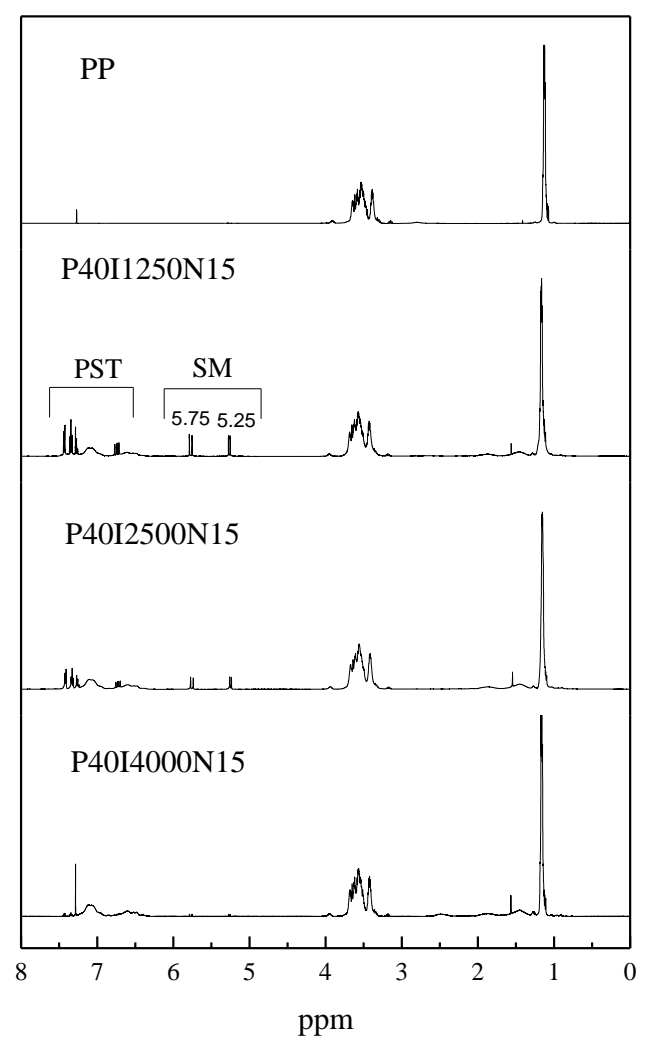

Fig. 16. ${ }^{1} \mathrm{H}$ NMR spectra of the PP and PPP varying the IM from 1.25 to 4 wt.\%.

As can be seen, the proton resonance of the polyether polyol is found within 3-4 and 1.1-1.2 ppm, the signals assigned to aromatic protons in the styrene units can be ranged between 6.5 and $7 \mathrm{ppm}$, and peaks of hydrogen in alpha position representative of the unreacted styrene monomer at 5.75 and 5.25 ppm, can be perfectly identified without any signal overlapping. Hence, it can be easily observed how the intensity due to the unreacted SM (hydrogen in alpha position) diminishes when the IM varies from 1.25 to 4 wt.\%.

In that way, by means of ${ }^{1} \mathrm{H}$ NMR, the weight ratios PS/PPP and SM/PPP of the polyols $\mathrm{PPP}_{6}$ to $\mathrm{PPP}_{8}$ were quantified. Besides, the SM loss was determined by mass balance. Table 4 summarizes the solid content (PS/PPP), the content of unreacted monomer in the PPPs (SM/PPP), the converted monomer (PS), unreacted monomer (SM) and the monomer loss $\left(\mathrm{SM}_{\mathrm{loss}}\right)$ as function of the initial monomer. 
Table 4. Solid content and unreacted monomer of PPPs and the PS, the SM and the $\mathrm{SM}_{\text {loss }}$ as function of the initial monomer.

\begin{tabular}{|c|c|c|c|c|c|}
\hline PPPs & $\begin{array}{c}\text { PS/PPP } \\
(\text { wt.\% })\end{array}$ & $\begin{array}{c}\text { SM/PPP } \\
(\text { wt.\% })\end{array}$ & \multicolumn{3}{|c|}{ Splitting the initial SM } \\
\cline { 4 - 6 } & & & PS & SM & SM $_{\text {loss }}$ \\
& & & $(w t . \%)$ & 26.29 & 38.00 \\
\hline P40I1250N15 & 16.84 & 12.40 & 35.71 & 19.00 & 29.92 \\
\hline P40I25005N15 & 23.20 & 8.63 & 51.08 & 2.24 & 21.46 \\
\hline P40I40005N15 & 33.38 & 0.98 & 76.29 & & \\
\hline
\end{tabular}

It is observed that the amount of unreacted SM for the different PPPs from ${ }^{1} \mathrm{H}$ NMR is very close to those obtained by TGA. Besides, it is confirmed that the product from the higher amount of initiator has the higher solid content. Hence, increasing the IM from 1.25 to $4.0 \mathrm{wt} \%$, it was possible to enhance the solid content from 16.84 to $33.38 \mathrm{wt} . \%$, respectively, for the same content of SM in the recipe and obtaining lower viscosity values than the commercial ones. It is worthy to mention that, the presence of unreacted SM had a big influence on the PPP viscosity, and its amount in the final PPP explains perfectly the previous viscosity trend $\eta \mathrm{PPP}_{6}<\eta \mathrm{PPP}_{7}<\eta \mathrm{PPP}$. In this table, it is also observed that the larger the initiator concentration, the lower the SM loss. This behaviour confirms that a high initiator concentration enlarges the nucleation process, favouring the fast reactivity and avoiding longer reaction times, which also promote the initiator deactivation and evidently the light monomer sweep away by the inert carrier gas. Besides, at this temperature a large amount of SM could be lost by vaporization. From these data is also possible to say that only a $76.3 \mathrm{wt} . \%$ of the initial monomer was transformed into solid particles.

To sum up, as result of the viscosity, morphology, particle size distribution, FTIR, TGA, GPC and ${ }^{1} \mathrm{H}$ NMR characterization it can be concluded that: the higher the AIBN concentration, the higher the monomer conversion and as consequence the viscosity of the PPP. On the other hand, the use of high initiator concentrations lead to a polydisperse product having big particles. According to these results, it has been found that the PPP synthesized at $110^{\circ} \mathrm{C}$, employing $1.5 \mathrm{wt} . \%$ of NAD, $40 \mathrm{wt} . \%$ of SM 
and 4 wt.\% of IM, presented the higher solids content, a great viscosity value (2590 mPa.s), a polydisperse product with a great morphology and a particles size with a $\mathrm{dv}_{0.5}$ of $42.92 \mu \mathrm{m}$ and a $\mathrm{dn}_{0.5}$ of $4.65 \mu \mathrm{m}$. As commented above and in order to improve the PPP polydispersity, increase the conversion of the SM to PS and reduce the SM loss, this polymer polyether polyol production was studied at lower reaction temperatures.

\subsubsection{Influence of the reaction temperature.}

Once, the conditions to obtain the best PPP has been selected, two new experiments at 70 and $80{ }^{\circ} \mathrm{C}$ have been carried out. It has been used the same nomenclature as before including an additional term $\mathrm{T}$ at the end, which refers to the reaction temperature in each experiment.

In Fig. 17 is shown the temperature influence on the particles size distribution, viscosity and morphology of the PPP.

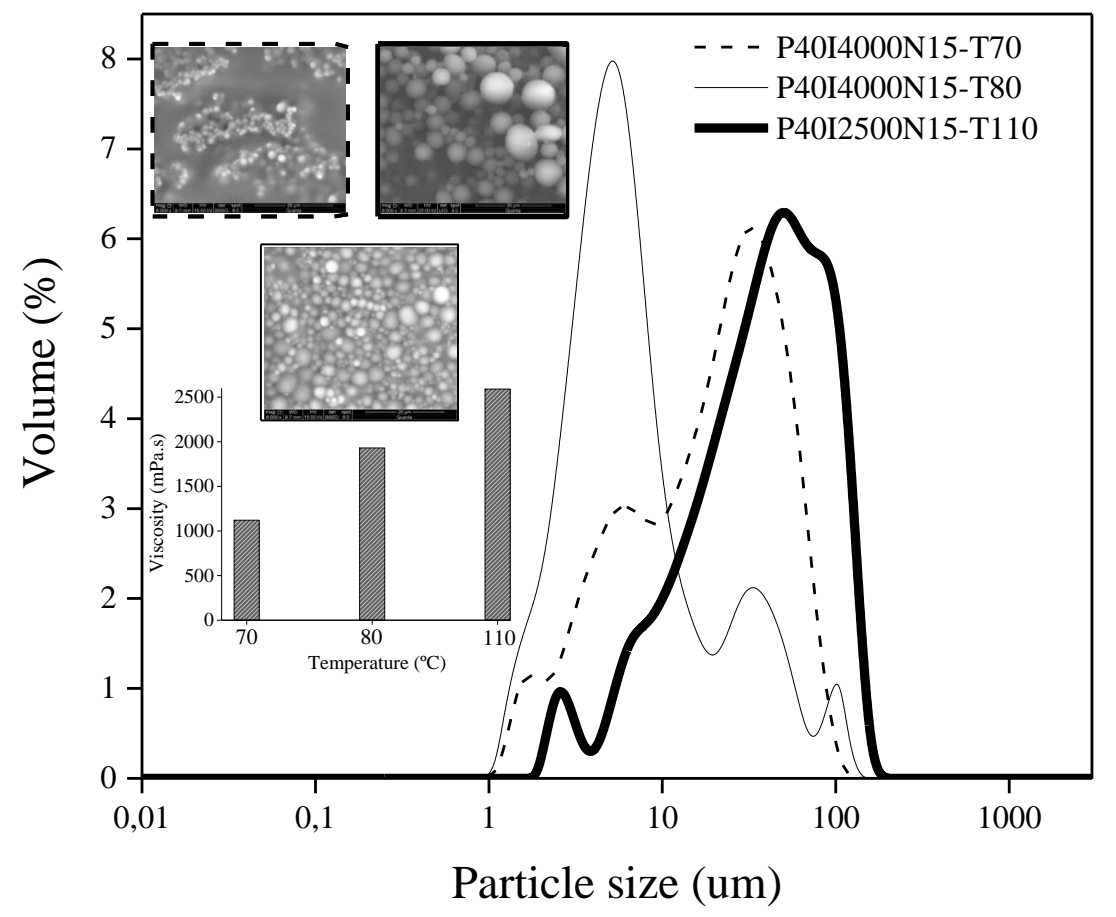

Fig. 17. Temperature influence in the particle size, viscosity and morphology of the PPP.

As it can be seen, the particle size of the P40I40005N15-T80 goes forward respect to the P40I40005N15-T110, indicating that with this temperature is possible to reduce the particle size 
polydispersity and leading spherical particles having similar $\mathrm{dv}_{0.5}(5.427 \mu \mathrm{m})$ and $\mathrm{dn}_{0.5}(1.711 \mu \mathrm{m})$. This particle size distribution is in concordance with the PPP from SAN, employing macromers of maleic anhydride as NAD [25].

Additionally, the viscosities of P40I40005N15-T70 (1120 mPa.s) and P40I40005N15-T80 (1930 mPa.s) are lower than that of P40I40005N15-T110 (2590 mPa.s), which can be related, as commented above, with the lower monomer conversion or the lower particle size distribution in the case of the P40I40005N15-T80.

Fig. 18 shows the TGA, GPC and the ${ }^{1} \mathrm{H}$ NMR analyses of synthesized PPPs at 70,80 and $110{ }^{\circ} \mathrm{C}$.

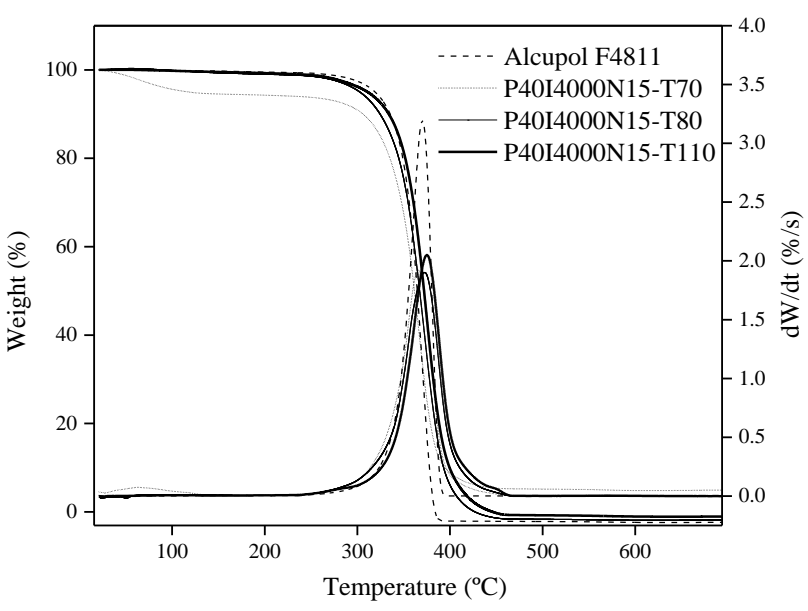

a)

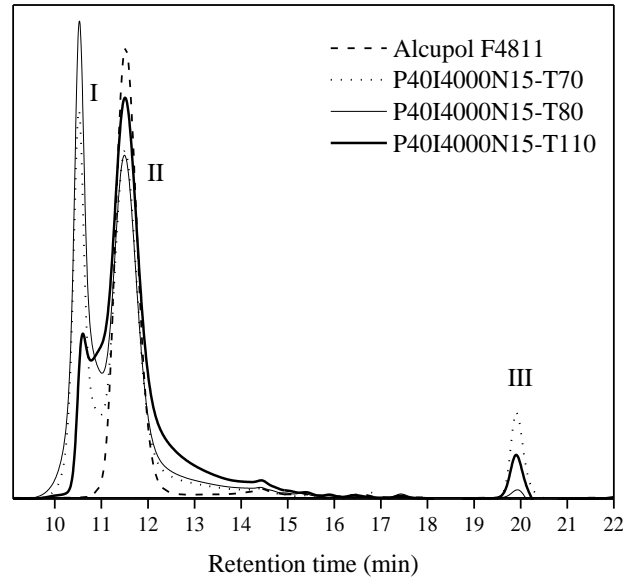

b)

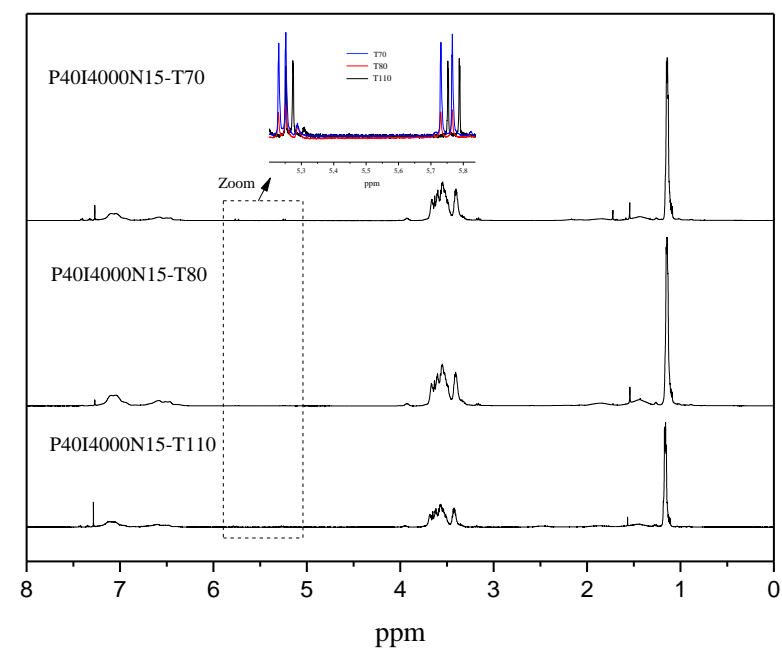

c)

Fig. 18. Characterization of PPPs at temperature function a) TGA analyses, b) GPC chromatograms and c) ${ }^{1} \mathrm{H}$ NMR spectra. 
From Fig. 18 a), the unreacted SM values in the PPP were undetected except at $70^{\circ} \mathrm{C}$, which present a weight loss of 5.934 wt.\%. Fig. 18b) also indicates that P40I40005N15-T70 has a high presence of this unreacted monomer. In the same way, analysing the Fig. 18c), the mass ratio SM/PPP of 2.41 wt.\% obtained from ${ }^{1} \mathrm{H}$ NMR spectrum of P40I40005N15-T70 is in concordance with the value estimated from TGA. Additionally, by this technique, weak proton resonances in the signals of the alpha hydrogens were observed for the P40I40005N15-T80 ${ }^{1} \mathrm{H}$ NMR spectrum, indicating that the $\mathrm{SM}$ conversion is almost complete at $80^{\circ} \mathrm{C}$, but a mass ratio SM/PPP of $0.383 \mathrm{wt} \%$ is obtained. This small quantity is also in agreement with the minimum area of the Peak III observed in the GPC chromatogram of this PPP.

Table 5 shows the solid content and the unreacted SM of the PPPs, the PS and PP molecular weights and the PS, SM and $\mathrm{SM}_{\text {loss }}$ as function of the initial monomer obtained from the above analyses.

Table 5. Solid content and unreacted SM of PPP, molecular weights of PS and PP and the PS, the $\mathrm{SM}$ and the $\mathrm{SM}_{\text {loss }}$ as function of the initial monomer.

\begin{tabular}{|c|c|c|c|c|c|c|c|}
\hline PPPs & $\begin{array}{c}\text { PS/PPP } \\
\text { (wt.\%) }\end{array}$ & $\begin{array}{c}\text { SM/PPP } \\
(\text { wt.\% })\end{array}$ & $\begin{array}{c}\text { PS } \\
\text { Mw } \\
(\mathrm{g} / \mathrm{mol})\end{array}$ & $\begin{array}{c}\text { Pw } \\
(\mathrm{g} / \mathrm{mol})\end{array}$ & $\begin{array}{c}\text { Splitting the initial SM } \\
\text { (wt.\%) }\end{array}$ & $\begin{array}{c}\text { SM } \\
(\text { wt.\%) }\end{array}$ & $\begin{array}{c}\mathrm{SM}_{\text {loss }} \\
\text { (wt.\%) }\end{array}$ \\
\hline P40I40005N15-T110 & 33.38 & 0.98 & 13288 & 3567 & 76.29 & 2.24 & 21.46 \\
\hline P40I40005N15-T80 & 38.69 & 0.38 & 14788 & 3598 & 95.28 & 0.94 & 3.78 \\
\hline P40I40005N15-T70 & 29.15 & 2.41 & 15044 & 3572 & 63.90 & 5.29 & 30.80 \\
\hline
\end{tabular}

As can be seen, the solid content (38.69 wt.\%) is maximum and close to the theoretical one (40 wt.\%) when the reaction is performed at a temperature of $80{ }^{\circ} \mathrm{C}$. It is also observed in this table that the maximum styrene conversion is achieved at this temperature, being a $19.93 \%$ higher than the SM conversion reached at $110^{\circ} \mathrm{C}$. This maximum conversion could explain the highest Peak I that is observed in the GPC for P40I40005N15-T80. Indicating that PS polymers of high molecular weight tends to be produced while the MW of PP remains practically constant. On the other hand, the high $\mathrm{SM}_{\text {loss }}$ obtained at $70^{\circ} \mathrm{C}$, indicates that this polymerization temperature is not enough to convert entirely the monomer and the light monomer is easily removed from the bulk by the carrier gas, promoting its loss (30.80 wt.\%). Hence, the lowest viscosity of the P40I40005N15-T70 is mainly 
related with the high SM content whereas the highest viscosity exhibited by the product of $110^{\circ} \mathrm{C}$ could be attributed to the biggest particle size of the PS polymer in the PPP. Thus, when a reaction temperature of $80^{\circ} \mathrm{C}$ is employed, the monomer condensation performance of the experimental setup is favoured, the initiator acts properly being possible to minimize the monomer losses, obtaining a high solids content in the final product and reducing the energetic costs are reduced.

To sum up, the optimal PPP containing 38.69 wt.\% of PS with a dv 0.5 of $5.427 \mu \mathrm{m}$ and $\mathrm{dn}_{0.5}$ of $1.711 \mu \mathrm{m}$, perfectly stabilized by hydrogen-bonding interaction between NAD and PP and reactivity of vinyl groups, from NAD and SM, has been developed. This PPP has been achieved at $80^{\circ} \mathrm{C}$, employing NAD and SM concentrations of 1.5 and $40 \mathrm{wt} . \%$, respectively, and a mass ratio of AIBN/monomer of $4 \mathrm{wt} . \%$. The viscosity of this PPP was $1930 \mathrm{mPa} \cdot \mathrm{s}$, which is within those of commercial ones, having SAN solids content of 25 and $42 \mathrm{wt} . \%, 1400$ and $4500 \mathrm{mPa} \cdot \mathrm{s}$, respectively [48].

\section{Conclusions}

For the first time in literature, a series of trifunctional PPP were obtained by means of employing a novel non-aqueous dispersant (NAD) based on a silica gel, which ensured a proper stabilization by a conjunction of two effects. On the one hand by means of hydrogen bonds between either hydroxyl groups or ether oxygen atoms of the trifunctional polyether polyol, and the hydroxyl groups contained in the NAD structure itself, and, on the other hand, the linkage between NAD and styrene monomer through their reactive vinyl groups, providing as result a segment with strong affinity to the dispersed polystyrene particles. This way, a proper stabilization was achieved and at the same time flocculation was avoided. The mass ratios PS and unreacted SM respect to the PPP and the molecular weights of PS and PP for the polymer polyether polyols were perfectly determined by ${ }^{1} \mathrm{H}$ NMR, TGA and GPC. It was found that the higher the NAD and the initiator concentrations, the higher the PPP viscosity. The viscosity of the PPP was directly affected by the particle size and inversely influenced by the undesirable unreacted monomer. In that way, the optimal PPP with the minimum unreacted SM was 
achieved by using the minimum NAD concentration (1.5 wt.\%), the maximum mass ratio initiator/monomer (4.0 wt.\%) and a temperature of $80^{\circ} \mathrm{C}$ for leading the minimum SM loss and PS particles of smaller size. The synthesized PPP presented a 38.69 wt.\% of PS, a dv 0.5 of $5.427 \mu \mathrm{m}$, a $\mathrm{dn}_{0.5}$ of $1.711 \mu \mathrm{m}$ and a viscosity value of $1930 \mathrm{mPa} . \mathrm{s}$. The viscosity and particle size of this PPP were in the range of the commercial ones.

\section{Acknowledgements}

We gratefully acknowledge funding from the Ministry of Economy and Competitiveness of Spain through the project Ref. CTQ2015-69299-R. 


\section{References}

[1] ADEME, Panorama du marched du polyuréthane et état de l'art de ses techniques de recyclage., (2014).

[2] R.W. Weigand. E, Present state of polyurethane recycling in Europe, In: Frisch KC, Klempner D, Prentice G, editors. Recycling of polyurethanes. Lancaster: Technomic Publishing;1999. p. 1-32 (1999). [3] A.M. Borreguero, J.L. Valverde, T. Peijs, J.F. Rodríguez, M. Carmona, Characterization of rigid polyurethane foams containing microencapsulated Rubitherm® RT27. Part i, Journal of Materials Science 45(16) (2010) 4462-4469.

[4] R.J. Borreguero. AM, Valverde. JL, Peijs. T, Carmona. M, Characterization of rigid polyurethane foams containing microencapsulted phase change materials: Microcapsules type effect. , Journal of Applied Polymer Science 128(1) (2013) 582-590.

[5] A.M. Borreguero, J.F. Rodríguez, J.L. Valverde, R. Arevalo, T. Peijs, M. Carmona, Characterization of rigid polyurethane foams containing microencapsulated Rubitherm ${ }^{\circledR}$ RT27: Catalyst effect. Part II, Journal of Materials Science 46(2) (2011) 347-356.

[6] F.B. Morris. DB, Rigid polyurethane foam: Refrigerator cabinet design and construction, International Journal of Refrigeration 2((2)) (1979) 105-112

[7] B.A. Simón D, de Lucas A, Gutiérrez C, Molero C, Rodríguez JF, The Handbook of Environmental Chemistry. Environment, Energy and Climate Change I: Environmental Chemistry of Pollutants and Wastes. Sustainable Polyurethanes: Chemical Recycling to Get It. , 32 (2015) 229-260.

[8] I. M., Chemistry and Technology of Polyols for Polyurethanes, Shawbury: Smithers Rapra Publishing (2005).

[9] W.G. Dounis DV, Structure property relationship of flexible polyurethane foam, Polymer 38 (1997) 2819-2828

[10] B.A. Simón D, de Lucas A, Rodríguez JF, Glycolysis of flexible polyurethane wastes containing polymeric polyols, Polymer Degrad Stabil 109 (2014) 115-121.

[11] d.L.A. Simón D, Rodríguez JF, Borreguero AM, Glycolysis of high resilience flexible polyurethane foams containing polyurethane dispersion polyol., Polym Degrad Stabil 133 (2016) 119-130.

[12] S. P., Method of preparing polyurethanes from liquid, stable, reactive, filmforming polymer/polyol mixtures formed by polymerizing an ethylenically unsaturated monomer in a polyol, USA 1967.

[13] W.S. Grace OM, Heyman DA, Graft polymer dispersion in a mixture of low molecular weight polyols and polyether polyols and polyurethane foams prepared therefrom, USA, 1985

[14] H.D. Ramlow GG, Grace OM, Reichel CJ, Hartman RJ, Process for the preparation of white graft polymer dispersions and flame-retardant polyurethane foams, USA, 1987.

[15] H.J. Gastinger RG, Stable polymer polyols in base polyols with molecular weight greater than 4000 using high molecular weight dispersants., USA, 1989.

[16] G.R. Hayes JE, Polymer polyol compositions containing a grafted polyol-polyacrylate dispersant, USA 1993.

[17] D.J. . Macromers for preparation of graft polymer polyol dispersions, USA 1993.

[18] H.J. Gastinger RG, Brennan ME, High styrene content stable polymer polyols using epoxy resinmodified polyols as dispersants, 1994.

[19] P.J. Lundgard RA, Jakubowski JJ, Kirchoff RA, Priester RD, Lidy WA. l. „, Dispersion of preformed polymer in a polyol, USA 2002.

[20] R.L. Adkins, S.A. Guelcher, J.R. Charron, J.E. Hayes, Low viscosity polymer polyols, Google Patents, 2006.

[21] J.H. Choi, S.M. Huh, J.K. Lee, J.Y. Choi, Method for preparing polymer polyol stabilizer using maleic anhydride, and polymer polyol stabilizer prepared thereby, Google Patents, 2011.

[22] H.R. van der Wal, R. Wevers, F. Van Damme, F.M. Casati, G. Kanaan, F. Pla, S. Hoppe, B. Noordover, C. Fonteix, Melt dispersion process for making polymer polyols, Google Patents, 2014.

[23] U.B.H.W. Simroth, Polymeric polyols and stabilizing systems, Google Patentes, 2012.

[24] H.V. Penfold, S.J. Holder, B.E. Mkenzie, Octadecyl acrylate - Methyl methacrylate block and gradient copolymers from ATRP: Comb-like stabilizers for the preparation of micro- and nano-particles of poly(methyl methacrylate) and poly(acrylonitrile) by non-aqueous dispersion polymerization, Polymer 51(9) (2010) 1904-1913. 
[25] J.P. Pérez, F.J. Martínez-Boza, P. Partal, Stability assessment of non-aqueous polymer dispersions through viscous flow and linear viscoelastic rheological tests, Polymer Testing 50 (2016) 164-171.

[26] S.K. Bharti, R. Roy, Quantitative 1H NMR spectroscopy, TrAC Trends in Analytical Chemistry 35 (2012) 5-26.

[27] A. FR, Estudio químico-físico de la preparación por el método Sol-Gel de materiales del sistema SiOZrO. Madrid, Madrid Complutense University., 1994.

[28] J. Liang, Y. Hu, Y. Wu, H. Chen, Facile formation of superhydrophobic silica-based surface on aluminum substrate with tetraethylorthosilicate and vinyltriethoxysilane as co-precursor and its corrosion resistant performance in corrosive $\mathrm{NaCl}$ aqueous solution, Surface and Coatings Technology 240 (2014) 145-153.

[29] Y.S. Li, P.B. Wright, R. Puritt, T. Tran, Vibrational spectroscopic studies of vinyltriethoxysilane solgel and its coating, Spectrochimica Acta - Part A: Molecular and Biomolecular Spectroscopy 60(12) (2004) 2759-2766.

[30] I. Mukherjee, J. Chen, H. Yin, Y. Wei, Use of sublimation for template removal from menthol templated mesoporous organosilica prepared via sol-gel process, Powder Technology 206(3) (2011) 214-217.

[31] M.H. Ibrahim, A.S. Abdullah, A. Nawabjan, N.M. Kassim, A.B. Mohammad, A.S.M. Supa'at, A thermooptic multimode interference switch structure based on vinyltriethoxysilane (VTES) hybrid organicinorganic sol-gel, Optik - International Journal for Light and Electron Optics 124(13) (2013) 1532-1535. [32] S.K. Parida, B.K. Mishra, Adsorption of styryl pyridinium dyes on polyethylene-glycol-treated silica, Colloids and Surfaces A: Physicochemical and Engineering Aspects 134(3) (1998) 249-255.

[33] A. Serrano, J. Martín del Campo, N. Peco, J.F. Rodriguez, M. Carmona, Influence of gelation step for preparing PEG-SiO2 shape-stabilized phase change materials by sol-gel method, Journal of Sol-Gel Science and Technology (2018).

[34] N.A. Agudelo, L.D. Perez, B.L. Lopez, A novel method for the synthesis of polystyrene-graft-silica particles using random copolymers based on styrene and triethoxyvinylsilane, Applied Surface Science 257(20) (2011) 8581-8586.

[35] A. Fidalgo, L.M. Ilharco, The defect structure of sol-gel-derived silica/polytetrahydrofuran hybrid films by FTIR, Journal of Non-Crystalline Solids 283(1) (2001) 144-154.

[36] A.L. Smith, CHAPTER 9 - Infrared Spectrometry A2 - RICHARDSON, J.H, in: R.V. Peterson (Ed.), Systematic Materials Analysis, Academic Press1974, pp. 255-300.

[37] M. Duldner, E. Bartha, S. Iancu, S. Capitanu, S. Nica, G. Sorina, Polyester-ether Polyols for Rigid Polyurethane Foams, Prepared from PET Wastes by a Clean Method, 2016.

[38] S. Caillol, M. Desroches, G. Boutevin, C. Loubat, R. Auvergne, B. Boutevin, Synthesis of new polyester polyols from epoxidized vegetable oils and biobased acids, European Journal of Lipid Science and Technology 114(12) (2012) 1447-1459.

[39] C. Bonhomme, C. Gervais, D. Laurencin, Recent NMR developments applied to organic-inorganic materials, Progress in Nuclear Magnetic Resonance Spectroscopy 77 (2014) 1-48.

[40] G. Hartmeyer, C. Marichal, B. Lebeau, S. Rigolet, P. Caullet, J. Hernandez, Speciation of Silanol Groups in Precipitated Silica Nanoparticles by 1H MAS NMR Spectroscopy, The Journal of Physical Chemistry C 111(26) (2007) 9066-9071.

[41] 김철현 이명의, Silicone Coating Compositions for LCD and Semiconductor Chip Protection, Google Patents, South Korea, 2010.

[42] M. Dibakar, D. S. Jeffrey, M. Kibret, R. Amin S., Bioactivity, Degradation, and Mechanical Properties of Poly(vinylpyrrolidone- $<\mathrm{i}>\mathrm{co}</ \mathrm{i}>-$ triethoxyvinylsilane)/Tertiary Bioactive Glass Hybrids, 2018.

[43] M. Málaga, Obtención, por polimerización con dispersión, de poliéteres poliméricos, University Complutense of Madrid. Faculty of Chemistry Sciences. Department of Chemical Engineering (1996).

[44] E.R.M. Edith Zapata C. RHB, Calificación de operación de un espectrómetro de fluorescencia de rayos X., Centro Nacional de Metrología (2006).

[45] F.M.S. Raúl Herrera Basurto FMT, Validación del método para la determinación de númro de onda por FT-IR en películas de poliestireno, Centro Nacional de Metrología, (2006).

[46] C.C. Seymour RB, Introducción a la química de los polímeros, Reverté (1995).

[47] Spectral Database for Organic Compounds SDBS 
[48] https://www.repsol.com/imagenes/global/es/polioles_polieter_es_tcm13-136515.pdf. (Accessed 20 March 2019 